OPEN ACCESS

Edited by:

Yu Tang,

University of Texas Southwestern Medical Center, United States

Reviewed by:

Pedro R. Lowenstein

University of Michigan Health System,

United States

Yvonne Nolan

University College Cork, Ireland

${ }^{*}$ Correspondence:

Howard J. Federoff

federoff@uci.edu

Received: 27 February 2017 Accepted: 18 May 2017 Published: 08 June 2017

Citation:

Subramaniam SR and Federoff HJ (2017) Targeting Microglial Activation

States as a Therapeutic Avenue in Parkinson's Disease.

Front. Aging Neurosci. 9:176. doi: 10.3389/fnagi.2017.00176

\section{Targeting Microglial Activation States as a Therapeutic Avenue in Parkinson's Disease}

\author{
Sudhakar R. Subramaniam and Howard J. Federoff* \\ Department of Neurology, University of California, Irvine, Irvine, CA, United States
}

Parkinson's disease (PD) is a chronic and progressive disorder characterized neuropathologically by loss of dopamine neurons in the substantia nigra, intracellular proteinaceous inclusions, reduction of dopaminergic terminals in the striatum, and increased neuroinflammatory cells. The consequent reduction of dopamine in the basal ganglia results in the classical parkinsonian motor phenotype. A growing body of evidence suggest that neuroinflammation mediated by microglia, the resident macrophage-like immune cells in the brain, play a contributory role in PD pathogenesis. Microglia participate in both physiological and pathological conditions. In the former, microglia restore the integrity of the central nervous system and, in the latter, they promote disease progression. Microglia acquire different activation states to modulate these cellular functions. Upon activation to the M1 phenotype, microglia elaborate pro-inflammatory cytokines and neurotoxic molecules promoting inflammation and cytotoxic responses. In contrast, when adopting the M2 phenotype microglia secrete anti-inflammatory gene products and trophic factors that promote repair, regeneration, and restore homeostasis. Relatively little is known about the different microglial activation states in PD and a better understanding is essential for developing putative neuroprotective agents. Targeting microglial activation states by suppressing their deleterious pro-inflammatory neurotoxicity and/or simultaneously enhancing their beneficial anti-inflammatory protective functions appear as a valid therapeutic approach for PD treatment. In this review, we summarize microglial functions and, their dual neurotoxic and neuroprotective role in PD. We also review molecules that modulate microglial activation states as a therapeutic option for PD treatment.

Keywords: Parkinson's disease, microglia, therapeutics, neuroinflammation, polarization

\section{INTRODUCTION}

Parkinson's disease (PD) is a common movement disorder and the second most prevalent neurodegenerative disorder worldwide, that affects nearly $2 \%$ of the elderly population. PD is characterized by loss of dopaminergic neurons in the substantia nigra pars compacta ( $\mathrm{SNpc}$ ) and consequently reduced dopamine (DA) levels in the basal ganglia, causing motor dysfunction (Figure 1). Lewy bodies, intracellular proteinaceous inclusions, are the pathological hallmark within PD brains. Lewy bodies contain fibrillar $\alpha$-synuclein among other proteins (Spillantini et al., 1997). It is evident that the immune system is involved in PD risk by genome-wide association 

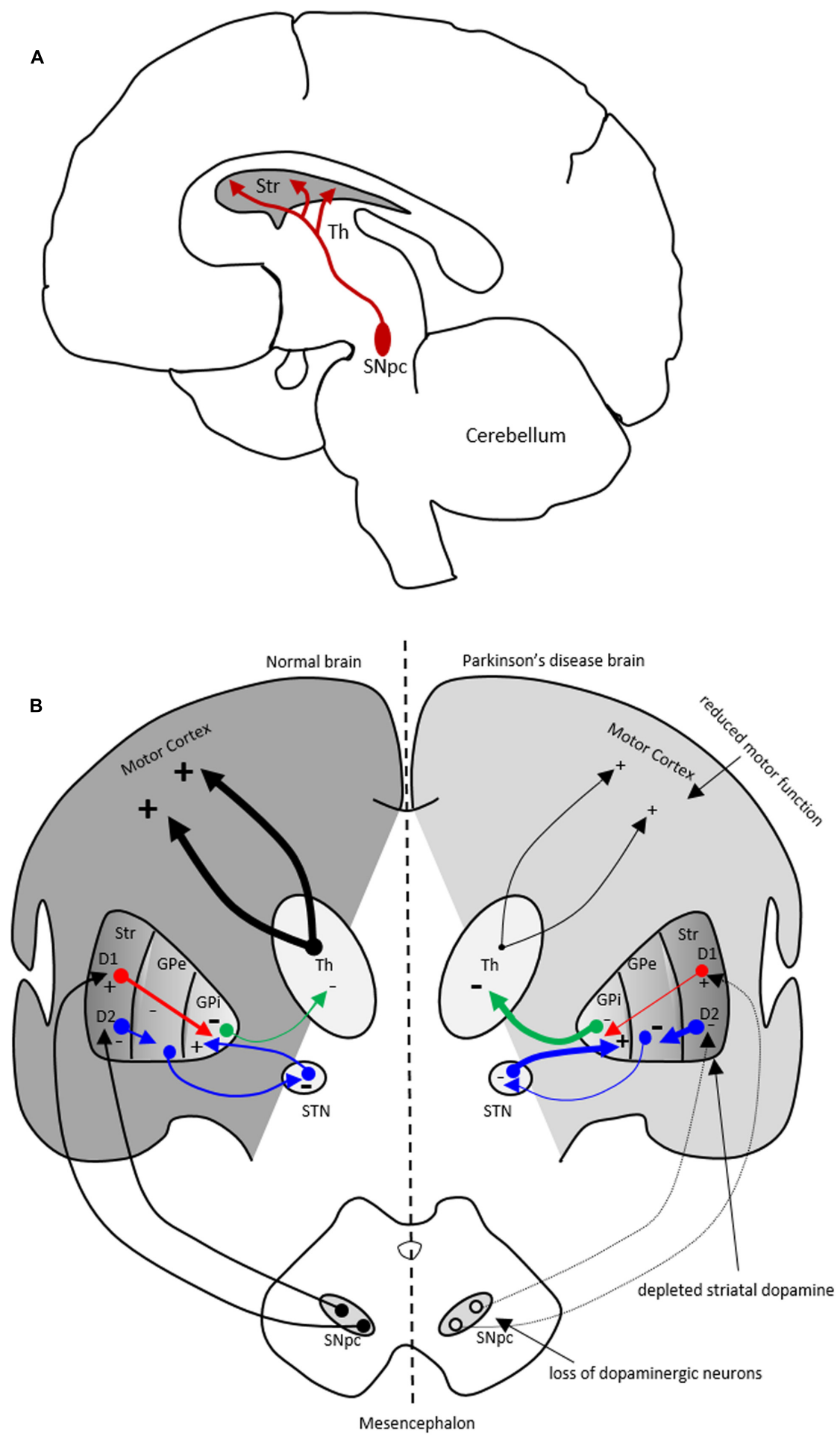

FIGURE 1 | The nigrostriatal dopaminergic pathway and motor basal ganglia circuitry in Parkinson's disease (PD) brain. (A) In the nigrostriatal pathway, the striatum, Str (caudate nucleus and putamen), receives dopaminergic innervation from the substantia nigra pars compacta (SNpc) in the midbrain. (B) A schematic showing normal motor basal ganglia circuitry (left side) and its irregularities in PD brain (right side), adapted from (Bjarkam and Sorensen, 2004). Normal brain (left): The dopaminergic afferent neurons from the SN synapse with GABAergic neurons which display either D1 or D2 dopaminergic receptors. These GABAergic populations project directly (red arrows) or indirectly (blue arrows; through globus pallidus externa, GPe, and subthalamic nucleus, STN) to globus pallidus interna (GPi). The output from the GPi (green arrows) to the thalamus is inhibitory and modulates normal motor function. PD brain (right): The loss of dopaminergic neurons in the SN and depletion of striatal dopamine leads to elevated inhibitory output from the GPi to the thalamus causing reduction in normal motor function. Inhibitory and excitatory inputs are marked as (-) and (+), respectively. The intensity of the inputs is marked with thickness of lines. Str, striatum; Th, thalamus. 
studies (GWAS), implicating the human leukocyte antigen (HLA) locus with sporadic PD (Hamza et al., 2010) and, as well, by the neuropathology in $\mathrm{PD}$ brains demonstrating highly activated microglial and T-cells (McGeer et al., 1988; Imamura et al., 2003). Several inflammatory markers have been identified in SNpc of PD brains including cytokines and neurotrophins (Nagatsu et al., 2000; Hunot and Hirsch, 2003). Also, widespread microglial activation is a concomitant in PD neuropathology (Gerhard et al., 2006). A meta-analysis of antiinflammatory drug trials revealed an association between nonsteroidal anti-inflammatory drugs (NSAIDs) use and reduced risk for developing PD possibly implicating neuroinflammatory processes in the disease (Gagne and Power, 2010). Evidence supports the conclusion that microglia, the brain resident macrophage-like immune cells, participate in the inflammatory response of the disease (Qian and Flood, 2008; Long-Smith et al., 2009; Moehle and West, 2015). In addition, other observations implicate peripheral immune cells in PD (Saunders et al., 2012; Funk et al., 2013; Chen et al., 2015). Together these data indicate that inflammation and microglial activation contribute to the in pathogenesis of $\mathrm{PD}$. Hence, immunomodulation might be a possible therapeutic avenue for PD.

The distribution of microglial M1/M2 phenotypes depends on the stage and severity of the disease. Understanding stagespecific switching of microglial phenotypes and the capacity to manipulate these transitions within appropriate time windows might be beneficial for PD therapy. In this review, we will outline different microglial activation states and provide evidence of M1/M2 activation states in PD. We will also discuss how manipulation of M1/M2 activation may be of potential therapeutic value.

\section{MICROGLIA FUNCTIONS}

In the central nervous system (CNS), the innate immune response is predominantly mediated by microglia and astrocytes. Microglia play a vital role in both physiological and pathological conditions. Tissue-specific macrophages can be found in most tissues of the body, whereas microglia are present distinctly in the brain. Microglia are derived from primitive yolk sac myeloid progenitors that seed the developing brain parenchyma (Alliot et al., 1999; Ginhoux and Jung, 2014). Microglia represent $10-15 \%$ of the total population of cells within the brain and manifest different morphologies across anatomic regions (Lawson et al., 1990; Mittelbronn et al., 2001). Microglia appear to be involved in several regulatory processes in the brain that are crucial for tissue development, maintenance of the neural environment and, response to injury and promoting repair. Similar to peripheral macrophages, microglia directly respond to pathogens and maintain cellular homeostasis by purging said pathogens, as well as dead cells and pathological gene products (Gehrmann et al., 1995; Bruce-Keller, 1999; Stevens et al., 2007; Tremblay et al., 2010; Olah et al., 2011; Paolicelli et al., 2011). In addition, microglial function can be altered by interactions with neurons, astrocytes, migrating T-cells, and the blood-brain barrier itself (Gonzalez et al., 2014).
Under physiological conditions, microglia acquire a neuralspecific, relatively inactive phenotype (Schmid et al., 2009) where they sample and inspect the local environment and other brain cells types (Davalos et al., 2005; Nimmerjahn et al., 2005). In a healthy brain, resting quiescent microglia exhibit a ramified morphology, with relatively long cytoplasmic protrusions, a stable cell body and little or no movement (Figure 2). Quiescent microglia extend processes into their surrounding environment (Nimmerjahn et al., 2005). This resting stage is partly maintained by signals conveyed by neuronal and astrocyte-derived factors (Neumann et al., 2009; Ransohoff and Cardona, 2010). The maintenance of this inactive state is regulated by several intrinsic factors like Runx1 (Runt-related transcription factor 1) and Irf8 (Interferon regulatory factor 8), and extrinsic factors such as TREM2 (triggering receptor also expressed on myeloid cells-2), chemokine CX3CR1 and CD200R (Kierdorf and Prinz, 2013). In the normal CNS environment, healthy neurons provide signals to microglia via secreted and membrane bound factors, such as CX3CL1, neurotransmitters, neurotrophins and CD22 (Sunnemark et al., 2005; Frank et al., 2006; Lyons et al., 2007; Pocock and Kettenmann, 2007). In addition, microglia express elevated levels of microRNA-124 which in turn reduces CD46, MHC-II (major histocompatibility complex II) and CD11b, to maintain the quiescent state (Conrad and Dittel, 2011).

\section{MICROGLIAL ACTIVATION: THE DUAL ROLES OF MICROGLIA}

As peripheral macrophages respond to endogenous stimuli promoting both pathogenic and protective functions, so do microglia. Upon exposure to endogenous stimuli microglia become activated. Among the gene products released by microglia are various substances including pro-inflammatory cytokines, neurotoxic proteins, chemokines, anti-inflammatory cytokines, and neurotrophic factors (Mahad and Ransohoff, 2003; Block et al., 2007; Benarroch, 2013; Nakagawa and Chiba, 2015). Microglia also display signaling immunoreceptors such as Toll-like receptors (TLRs), scavenger receptors (SRs), nucleotide binding oligomerization domains (NODs) and NODlike receptors (Ransohoff and Brown, 2012). Fundamentally, the two polar states of microglia, the M1 and M2 phenotypes are associated phenomenologically with injury and homeostasis, respectively (as described below). Differential states of microglial activation within an injured tissue evolve during an inflammatory epoch (Graeber, 2010).

\section{M1 Polarization State}

When classically activated, microglia acquire the M1 phenotype, characterized by pro-inflammatory and pro-killing functions that serve as the first line of defense. In M1 microglial activation state both secreted factors and cellular markers are dysregulated (Table 1). During M1 polarization (driving from another, often resting state), microglia release pro-inflammatory cytokines: interleukin-1 $\beta$ (IL-1 $\beta$ ), IL-6, IL-12, IL-17, IL-18, IL23 , tumor necrosis factor- $\alpha$ (TNF- $\alpha)$, interferon- $\gamma($ IFN- $\gamma$ ) and 


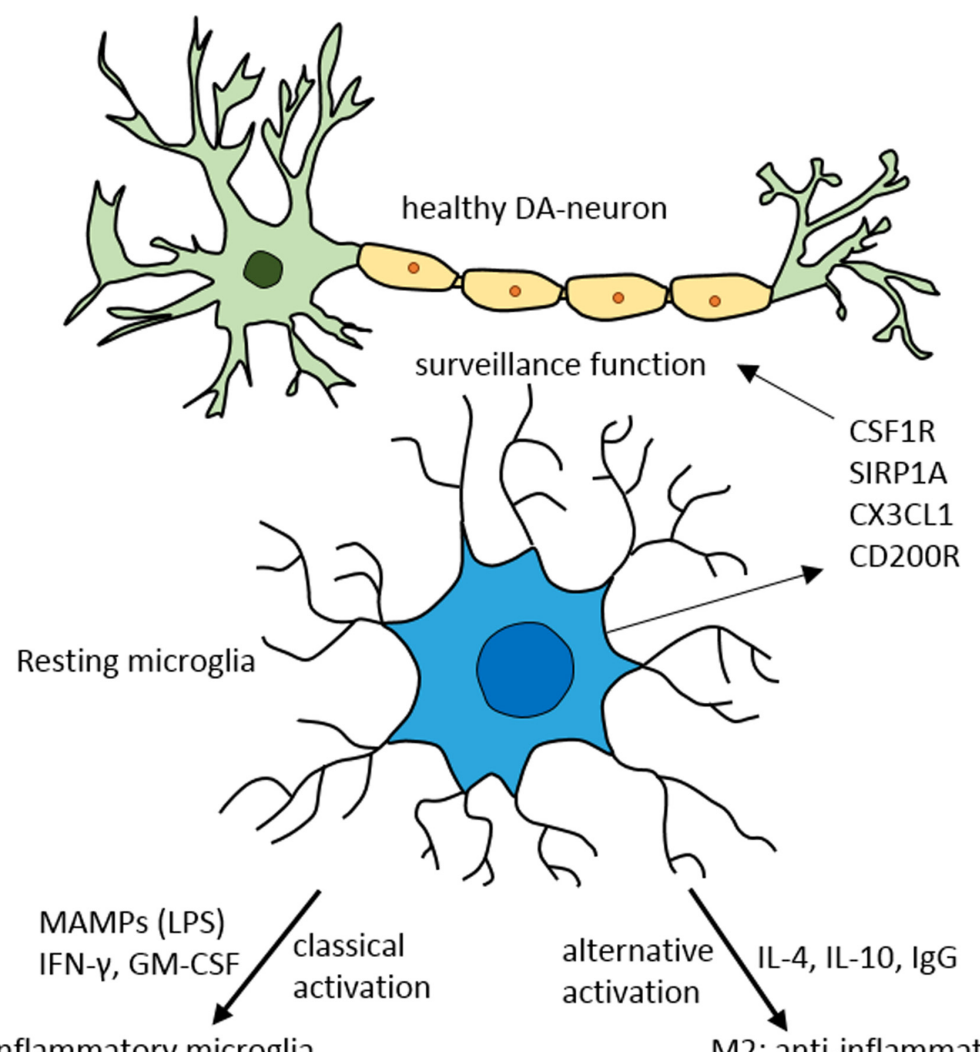

M1: proinflammatory microglia
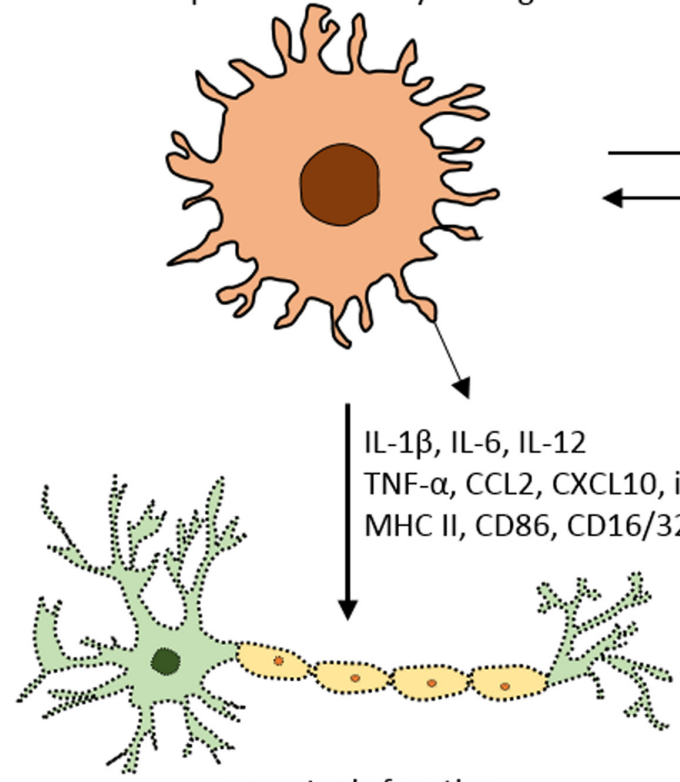

neurotoxic function
M2: anti-inflammatory microglia

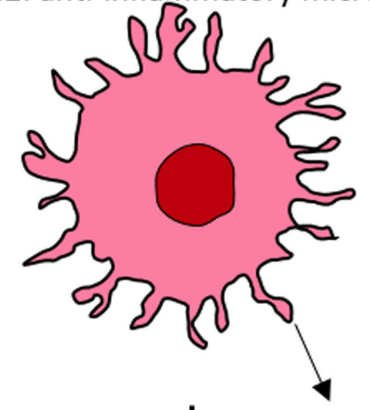

FIGURE 2 | Schematic of microglial polarization states and function. In normal physiological conditions microglia acquire the surveillance phenotype to maintain all CNS cell types including neurons. To maintain this surveillance state, microglia secrete several factors including colony stimulating factor 1 receptor (CSF1R), signal regulatory protein CD172 (SIRP1A), chemokine CX3CL1 and CD200R. Upon classical activation when triggered by LPS, IFN- $\gamma$, or GM-CSF microglia acquire M1 pro-inflammatory phenotype leading to neurotoxicity by secreting several pro-inflammatory substances (for detailed list, see Table 1). When activated alternatively by IL-1, IgG, or IL-10 microglia attain M2 anti-inflammatory state prompting neuroprotection through secretion of variety of substances (for detailed list, see Table 1). Arg1, arginase 1; CCL, chemokine (C-C motif) ligand; CD, cluster of differentiation; CSF1R, colony stimulating factor 1 receptor; CXCL, chemokine (C-X-C motif) ligand; Fizz1, found in inflammatory zone; IL, interleukin; GM-CSF, granulocyte-macrophage colony-stimulating factor; IFN- $\gamma$, interferon- $\gamma$; iNOS, inducible nitric oxide synthase; LPS, lipopolysaccharide; MAMPs, microbe-associated molecular patterns; MHC-II, major histocompatibility complex II; SIRP1A, signal regulatory protein CD172; SOCS3, suppressor of cytokine signaling-3; TNF- $\alpha$, tumor necrosis factor- $\alpha$; Ym1, chitinase-like protein. 
TABLE 1 | Microglial polarization states and substances produced.

\begin{tabular}{|c|c|c|c|}
\hline Activation type/function & Source & Substances produced & Reference \\
\hline $\begin{array}{l}\text { M1 (classical activation): } \\
\text { pro-inflammatory and pro-killing }\end{array}$ & LPS, IFN- $\gamma$ & $\begin{array}{l}\text { Cytokines: IL-1 } \beta, \text { IL-6, IL-12, IL-17, } \\
\text { IL-18, IL-23, TNF- } \alpha \\
\text { Markers: CD86, MHC-II } \\
\text { Chemokines: CCL2 } \\
\text { Metabolic enzyme/redox } \\
\text { molecules: iNOS, COX-2, reactive } \\
\text { oxygen species and reactive nitrogen } \\
\text { species prostaglandin E2 }\end{array}$ & $\begin{array}{l}\text { Mahad and Ransohoff, 2003; Kawanokuchi et al., } 2006 \\
\text { Kawanokuchi et al., 2008; Loane and Byrnes, 2010; } \\
\text { Benarroch, 2013; Chhor et al., 2013; Franco and } \\
\text { Fernandez-Suarez, 2015; Nakagawa and Chiba, } 2015\end{array}$ \\
\hline
\end{tabular}

M2a (alternative activation): IL-4, IL-13

tissue repair and phagocytosis

M2b (alternative activation):

recruitment of regulatory $T$ cells

M2c (alternative activation):

anti-inflammatory and healing
Fc $\gamma$ receptors, TLRs and

immune complexes (lgG)

IL-10, TGF- $\beta$ and

glucocorticoids
Mahad and Ransohoff, 2003; Loane and Byrnes, 2010, Benarroch, 2013; Chhor et al., 2013; Franco and Fernandez-Suarez, 2015; Nakagawa and Chiba, 2015
Cytokines: IL-10
Markers: CD206, SR-A1, SR-B1, Arg1, Ym1, Fizz1

Others: extracellular matrix proteins, PPAR

Cytokines: IL-1 $\beta$, IL-6, IL-10, TNF- $\alpha$

Markers: CD86, MHC-II

Others: SOCS3, COX-2, Sphk

Cytokines: IL-10, TGF- $\beta$

Markers: CD163

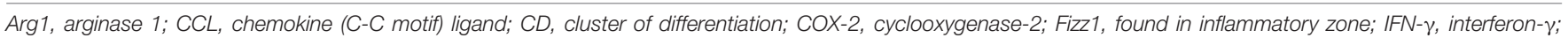

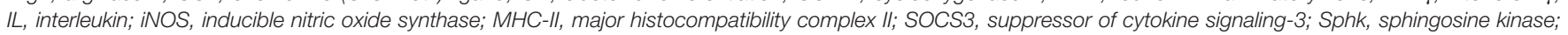
SR-A1, scavenger receptor class A1; SR-B1, scavenger receptor class B1; TGF, transforming growth factor; TNF- $\alpha$, tumor necrosis factor- $\alpha$; Ym1, chitinase-like protein.

nitric oxide, and chemokines: CCL2 (Mahad and Ransohoff, 2003; Kawanokuchi et al., 2006, 2008; Loane and Byrnes, 2010; Benarroch, 2013; Nakagawa and Chiba, 2015). Also upon M1 activation microglia appear to present phenotypic markers: inducible nitric oxide synthase (iNOS), cyclooxygenase-2 (COX2), MHC-II, and CD86 (cluster of differentiation marker 86) (Chhor et al., 2013; Franco and Fernandez-Suarez, 2015) and, other substances including reactive oxygen species (ROS), reactive nitrogen species, and prostaglandin E2 (Benarroch, 2013; Nakagawa and Chiba, 2015). These orchestrated processes are to purge foreign pathogens and polarize T-cells to elicit an adaptive immune response.

The M1 phenotype of microglia can be induced in experimental models using microbe-associated molecular pattern molecules such as lipopolysaccharide (LPS), an endotoxin present in the cell membranes of Gram-negative bacteria, or others related to infections such as IFN- $\gamma$ (Figure 3; Loane and Byrnes, 2010; Boche et al., 2013). Similarly, an aseptic inflammatory response also occurs after exposure to trauma or ischemiareperfusion injury or chemical injury.

IFN- $\gamma$ utilizes the JAK/STAT (Janus kinase/signal transducer and activator of transcription) signaling pathway to activate the M1 phenotype. M1 activation by IFN- $\gamma$ occurs through activation of IFN $-\gamma$ receptors 1 and 2 (IFN- $\gamma$ R $1 / 2)$ leading to JAK1/2 activation, phosphorylation and the nuclear translocation of STAT1 along with interferon regulatory factors (IRFs). This signaling cascade promotes expression of M1-associated cytokines, chemokines, and other genes (Hu and Ivashkiv, 2009; Boche et al., 2013).

LPS induces M1 activation via TLRs, which recognize specific patterns of microbial macromolecules. LPS binds to TLR4 on the cell surface that is coupled to MD2 (myeloid differentiation protein 2) (TLR/MD2) with participation of co-receptors CD14 and LBP (LPS-binding protein).
LPS binding to TLR4 results in activation through MyD88 (myeloid differentiation primary response protein 88 ) and TRIF (TIR domain-containing adaptor inducing IFN- $\beta$ ), and transcription factors such as NF- $\kappa$ B (nuclear factor kappa B), STAT5, and IRFs (Takeda and Akira, 2004). This causes transcriptional upregulation of M1-associated cytokines, chemokines and other genes. Alternative M1 activation stimulation through granulocyte-macrophage colonystimulating factor (GM-CSF) has been demonstrated recently (Lacey et al., 2012). However, unlike LPS and IFN- $\gamma$, GM-CSF is reported to instigate pleomorphic activation states that shows characteristics of both M1 and M2 phenotypes (Weisser et al., 2013). Figure 3 (left side) provides further details on M1 activation.

\section{M2 Polarization State}

The alternative M2 microglial activation state is involved in various events including immunoregulation, inflammation dampening, and repair and injury resolution. M2 microglia is morphologically characterized by enlarged cell bodies (Figure 2). M2 microglial activation produces an array of mediators such as anti-inflammatory cytokines, extracellular matrix proteins, glucocorticoids, and other substances.

Presently, the mechanism of M2 activation in microglia is poorly understood compared to macrophages. It is believed that microglia can develop diverse M2 phenotypes similar to macrophages (Morgan et al., 2005; Herber et al., 2006; Schwartz et al., 2006). The characteristics of M2 polarization of microglia parallel that of the macrophages (Chhor et al., 2013; Freilich et al., 2013) producing IL-4 and IL-10 stimulation through Arg1 (arginase 1), Ym1 (chitinase-like protein), Fizz1 (found in inflammatory zone), and PPAR (peroxisome proliferatoractivated receptor) (Michelucci et al., 2009). M2 macrophage activation is sub-classified into M2a, M2b, and M2c, and these 


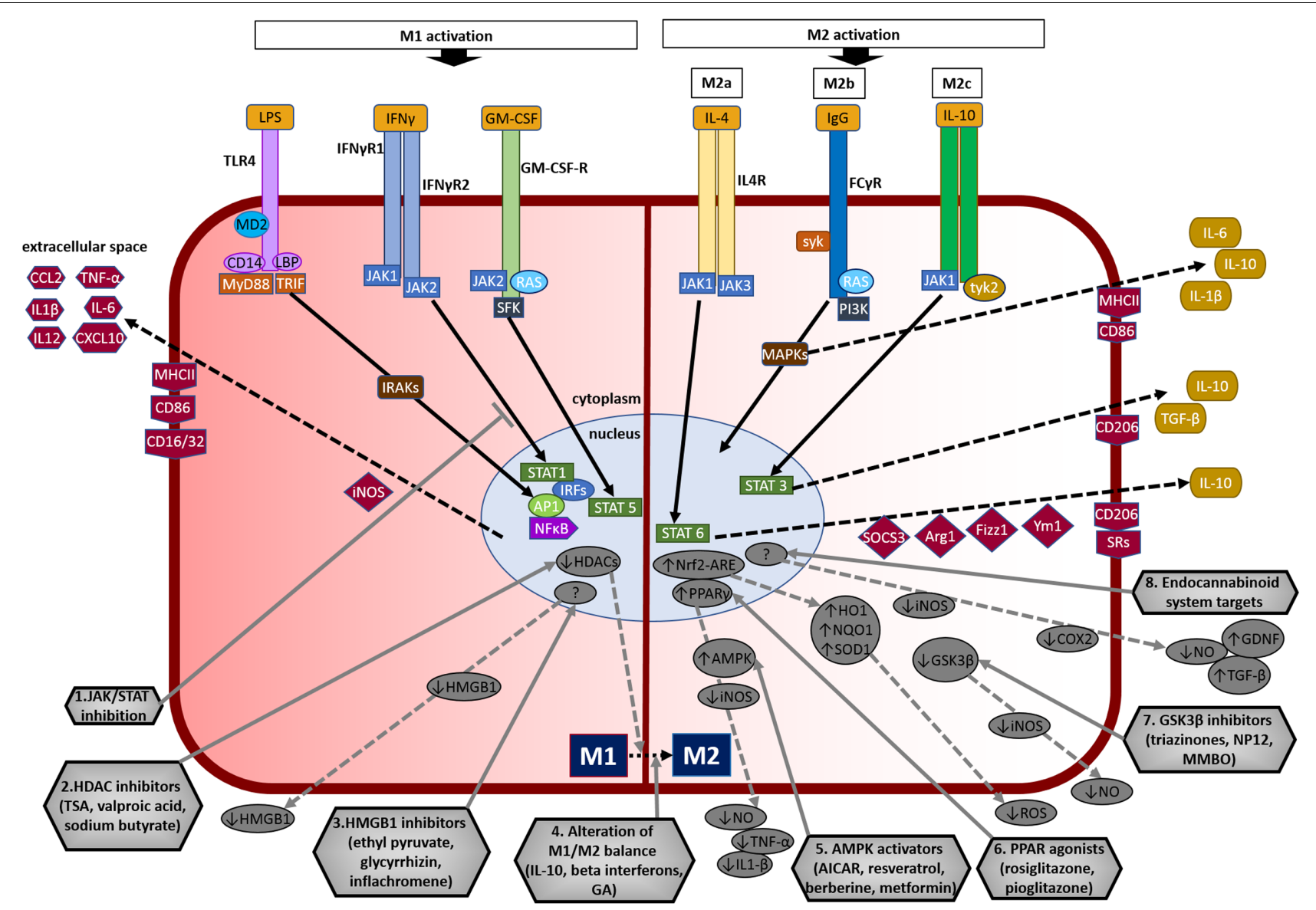

FIGURE 3 | Overview of microglial M1 and M2 signaling in neurodegeneration, and potential targets for neuroprotection. The left side of the figure compartment shows M1 microglial phenotype and its major signaling pathways. LPS binds to TLR4 on the cell surface which is coupled to MD2 (TLR/MD2) with participation of co-receptors CD14 and LBP (LPS-binding protein), activates interleukin-1 receptor-associated kinases (IRAKs) through MyD88 and TRIF that causes translocation of transcription factors such as NF-kB, STAT5, activator protein-1 (AP1), and interferon regulatory factors (IRFs) to the nucleus. M1 activation by IFN- $\gamma$ occurs through IFN- $\gamma$ receptors 1 and 2 (IFN- $\gamma$ R1/2) leading to the recruitment of Janus kinase 1 and 2 (JAK1/2) that phosphorylate and translocate STAT1 and IRFs to the nucleus. M1 activation stimulation through granulocyte-macrophage colony-stimulating factor (GM-CSF) occurs when GM-CSF binds to its receptor GM-CSF-R, which activates rat sarcoma oncoproteins (RAS), JAK2, and SFK, and causes translocation of STAT5 to the nucleus. The translocation of NF-KB, STAT1, STAT5, AP1, and IRFs to the nucleus causes upregulation of intracellular iNOS and cell surface markers (CD86, CD16/32, MHC-II). M1 stimulation also causes transcriptional upregulation of M1-associated pro-inflammatory cytokines (IL-1 $\beta$, IL-6, IL-12, TNF- $\alpha$ ) and chemokines (CCL2, CXCL10). The right side of the figure compartment shows various M2 microglial phenotypes and major signaling pathways involved. M2 activation can be classified into M2a, M2b, and M2c. M2a state is induced mainly by IL-4. IL-4 binds to IL-4R, which stimulates JAK1 or JAK3 that causes translocation of STAT6 to the nucleus leading to transcription of M2a-associated genes including IL-10, cell surface markers (CD206, scavenger receptors, SRs), and intracellular components such as suppressor of cytokine signaling 3 (SOCS3), Ym1 (chitinase-like protein) and Fizz1 (found in inflammatory zone). The M2b activation state, which has some M1 response characteristics, is stimulated when TLRs fuse $\mathrm{F} c \gamma$ receptors, which then bind to $\mathrm{IgG}$ (B cells) to derive the M2b phenotype. M2b activation results in secretion of IL-10 and, cell surface markers (CD86, MHC-II). M2C activation is induced by IL-10 which stimulates the IL-10 Receptor 1 and 2 subunits that activates JAK1 leading to the translocation of STAT3 to the nucleus. STAT3 translocation inhibits M1-associated pro-inflammatory cytokines and upregulation of IL-10, TGF- $\beta$ and the cell surface marker CD206. M2C state plays an important role in immunoregulation, matrix deposition and tissue remodeling. The bottom half of the figure shows potential therapeutic microglial targets for neuroprotection. (1) JAK/STAT inhibition: M1 phenotype is induced via the JAK/STAT signaling pathway and inhibition of this pathway may suppress the downstream M1-associated pro-inflammatory genes. (2) Histone deacetylase (HDAC) inhibitors: Histone acetylation is increased in M1 state that may lead to the expression and release of pro-inflammatory cytokines. HDAC inhibitors prevent neurodegeneration by shifting microglia toward protective M2 phenotype and anti-inflammatory mechanisms. (3) Microglia-produced high-mobility group box-1 (HMGB1) inhibitors: HMGB1 is a pro-inflammatory cytokine released by microglia which is toxic to neurons. HMGB1 inhibitors show neuroprotection by binding to HMGB1 and inhibiting its cytokine-like activity. (4) Alteration of M1/M2 balance: These agents promote the shift M1 pro-inflammatory phenotype toward protective M2 phenotype, and also exhibit neuroprotection by counteracting excessive pro-inflammatory M1 cytokines. (5) Adenosine monophosphate-activated protein kinase (AMPK) activators: AMPK activators act by inhibiting the expression of pro-inflammatory cytokines and iNOS by reducing NF-kB activation. (6) Peroxisome proliferator-activated receptor (PPAR) agonists: PPAR agonists exhibit neuroprotection by upregulating AMPK and protective genes, reducing oxidative damage, maintaining mitochondrial function and anti-inflammatory mechanisms. (7) Glycogen synthase kinase-3 $\beta$ (GSK3 $\beta$ ) inhibitors: GSK3 $\beta$ regulate microglial migration, inflammation, and neurotoxicity through astrocytes. GSK3 $\beta$ inhibitors decrease inflammation by reducing iNOS expression and release of nitric oxide (NO). (8) Endocannabinoid system targets: Agents that target the endogenous cannabinoid ligands anandamide and 2-arachidonoylglycerol (2-AG) increase TGF- $\beta$, arginase 1 and glial cell line-derived neurotrophic factor (GDNF), and reduce iNOS and COX-2, expression. AICAR, 5-amino-4-imidazole carboxamide riboside; GA, glatiramer acetate; HO-1, heme oxygenase 1; MMBO, 2-methyl-5-methylsulfinylphenyl-1-benzofuranyl1,3,4-oxadiazole; NP-12, tideglusib; NQO1, NAD(P)H quinone dehydrogenase 1; Nrf2, nuclear erythroid 2-related factor 2; ARE, antioxidant response element; SOD1, superoxide dismutase 1; TSA, trichostatin A. 
activation states may be envisaged to microglia (Boche et al., 2013; Figure 3 and Table 1). The M2a state is induced by IL-4 or IL-13 and, is associated with tissue repair and phagocytosis. IL-4 binds to different receptor pairs, which stimulate JAK1 or JAK3 and activates STAT6 leading to transcription of M2a-associated genes including CD206, suppressor of cytokine signaling 3 (SOCS3) and SRs. The M2b activation state is stimulated by engagement of TLRs and the IL-1 receptor, and is involved in the recruitment of regulatory T cells. Activated TLRs fuse Fc $\gamma$ receptors, which then bind to IgG (B cells) to derive the M2b phenotype. M2b activation results in secretion of IL-10, CD86 (on cell surface) and MHC-II. M2c activation state is induced by IL-10 and glucocorticoid hormones, and is involved in anti-inflammatory and healing functions. IL-10 stimulates the IL-10R1 and IL-10R2 which activate JAK1 leading to the translocation of STAT3 into the nucleus. STAT3 translocation suppresses most of the M1associated pro-inflammatory cytokines (Franco and FernandezSuarez, 2015; Michell-Robinson et al., 2015). Overall, it is considered that the M2 activation promotes healing and tissue repair whereas the M1 activation state is the first line of defense with pro-killing functions. Please see Figure 3 (right side) for details on M2 activation.

\section{Polarization Transitions}

The transition from the M1 pro-inflammatory state to the regulatory or anti-inflammatory M2 phenotype is thought to assist improved functional outcomes and restore homeostasis (Orihuela et al., 2016). Recently, histone H3K27me3 demethylase Jumonji was shown to be essential for M2 polarization and downregulation of the M1 phenotype (Tang et al., 2014). The induction of M1 phenotype is a relatively standard response during injury. For peripheral immune cells it is thought that M1 polarization is terminal and the cells die during the inflammatory response (Orihuela et al., 2016). Although a shift from M1 to the M2 phenotype is considered rare for peripheral immune cells, the microglia can shift from M1 to M2 phenotype when exposed to IL-10, glatiramer acetate, beta interferons, PPAR $\gamma$ agonists and other molecules discussed in the later section. Although, the M1 and M2 microglial phenotypes vastly differ in their function, different subpopulations in an injury environment may express specific phenotypes resulting in concurrent expression of M1and M2-related factors or mixed M1/M2 phenotypes (ZieglerHeitbrock et al., 2010; Pettersen et al., 2011; Vogel et al., 2013). The potential to pharmacologically promote a microglial M1 to M2 shift may have therapeutic implications in the setting of neurodegenerative diseases associated with neuroinflammation.

\section{MICROGLIA-MEDIATED INFLAMMATION IN PD}

The involvement of innate immunity in PD was first proposed by McGeer et al. (1988) when brain from PD patients showed high levels of reactive microglia that were positive for human leukocyte antigen-D related (HLA-DR) in the substantia nigra and putamen. GWAS indicate that variants in the HLA region are linked to sporadic PD (Hamza et al., 2010; HillBurns et al., 2011). Activated microglia in PD brain appear responsible for exacerbating neurodegeneration (McGeer and McGeer, 2004), and the exposure of human neuromelanin discharged from dead DA neurons cause chemotaxis and increases the pro-inflammatory substances in microglial cultures (Wilms et al., 2007). M1 activation-associated inflammatory markers such as MHC-II (Imamura et al., 2003), TNF- $\alpha$ and IL-6 (Boka et al., 1994; Imamura et al., 2003) have been reported in patients with PD. Recent positron emission tomography (PET) studies show that PD patients have cortical microglial activation and lower brain glucose metabolism early in the disease, and imply that microglial activation may be a contributing factor in the disease progression (Edison et al., 2013). PET with inflammatory ligands show elevation in several areas of the basal ganglia involved in PD pathology (Gerhard et al., 2006; Edison et al., 2013; Iannaccone et al., 2013). TLR2 is increased in postmortem PD brain tissue, which correlates with pathological $\alpha$-synuclein deposition. The neuronal TLR2 rather than glial expression of TLR2 is significantly elevated in PD brain and correlates with disease progression. In addition, TLR2 is strongly localized in $\alpha$-synuclein positive Lewy bodies (Dzamko et al., 2017). These observations highlight the crucial role of neuroinflammation in PD pathogenesis.

\section{PERIPHERAL INFLAMMATION IN PD}

"The dual hit theory" of PD development states that a neurotropic pathogen enters the brain by nasal and/or gastric route by axonal transport, the latter via the vagus nerve (Braak et al., 2003; Hawkes et al., 2009). There is evidence that some forms of $\alpha$-synuclein can be transmitted from the gut to the brain (Pan-Montojo et al., 2010; Ulusoy et al., 2013; Holmqvist et al., 2014). Instillation of rotenone into the rodent stomach exhibits progressive pathological $\alpha$-synuclein inclusions in the enteric nervous system, the vagus nerve and subsequently in the brain stem (Pan-Montojo et al., 2010). Vagotomy prevents transport of pathological proteins from the gut to CNS (Phillips et al., 2008; PanMontojo et al., 2012). A recent study in Danish patients reveals that those who underwent full truncal vagotomy had lower risk for $\mathrm{PD}$, suggesting that the vagus nerve might be critically involved in PD pathogenesis (Svensson et al., 2015). Another clinical study reports that serum levels of the pro-inflammatory cytokine IL-1 $\beta$ discriminated asymptomatic LRRK2-G2019S carriers from controls and suggests that peripheral inflammation is greater in a percentage of subjects carrying LRRK2-G2019S mutation (Dzamko et al., 2016).

The major peripheral immune cells, T-lymphocytes and B-lymphocytes, are not found in the CNS in normal biological conditions. However, with peripheral inflammation such as infection or injury, blood monocytes, and tissueresident immune cells are activated and secrete variety of pro-inflammatory mediators including TNF- $\alpha$, IL-6, and 
IL-1 $\beta$. These pro-inflammatory mediators cross the bloodbrain barrier leading to the activation of brain resident microglia, which then triggers a neuroinflammatory cascade. The blood-brain barrier is considered to be impermeable to external pathogens and circulating macrophages, hence serving as an additional line of defense to the CNS. Nevertheless, damage to the integrity of the blood-brain barrier renders the brain vulnerable. PET studies on patients with PD reveal dysfunctional blood-brain barrier (Kortekaas et al., 2005). Damage to the blood-brain barrier in rats induce degeneration of dopaminergic neurons in the substantia nigra and activate glial cells (Rite et al., 2007). $\mathrm{CD}^{+}$and $\mathrm{CD}^{+} \mathrm{T}$ cells are observed in the postmortem human PD brain and MPTP (1-methyl-4-phenyl-1,2,3,6-tetrahydropyridine) mouse model of PD during its neurodegenerative phase suggesting $\mathrm{T}$ cellmediated dopaminergic toxicity as a putative mechanism (Brochard et al., 2009). Moreover, rats with ulcerative colitis are more susceptible to LPS-induced dopaminergic neuron loss, blood-brain barrier permeability, microglial activation, and generation of pro-inflammatory mediators suggesting that peripheral inflammation may increase the risk of PD (Villaran et al., 2010). A recent study in the acute MPTP mouse model where nigrostriatal pathologies are not robust show that administration of chemokines [regulated on activation, normal $\mathrm{T}$ cell expressed and secreted (RANTES) and eotaxin] that facilitate $\mathrm{T}$ cell trafficking can lead to marked nigral $\alpha$-synuclein pathology, loss of dopaminergic neurons and striatal neurotransmitter depletion, glial-associated inflammation, and motor impairments. However, systemic administration of pro-inflammatory cytokines, TNF- $\alpha$ and IL- $1 \beta$, did not induce such disease pathologies in this acute MPTP model (Chandra et al., 2017). Taken together these studies suggest a more direct link between peripheral inflammation and, potential to elicit and affect the timing of PD onset.

\section{GENETIC FACTORS LINKED TO INFLAMMATION IN PD}

Mutations in leucine-rich repeat kinase (LRRK2, PARK8) are linked with autosomal dominantly inherited PD and is the greatest known genetic contributor to PD. LRRK2-G2019S mutation in the kinase domain is the most common mutation in both familial and sporadic form of the disease (Goldwurm et al., 2005). GWAS show that the genetic locus containing the LRRK2 gene presents a risk factor for sporadic PD (Singleton and Hardy, 2011). Interestingly, GWAS implicate LRRK2 as a major susceptibility gene in inflammatory bowel diseases that involve chronic inflammation (Barrett et al., 2008; Liu and Lenardo, 2012). LRRK2 is reported to be a target gene for IFN- $\gamma$, a M1-activation-associated pro-inflammatory cytokine. LRRK2 expression is elevated in human intestinal tissue of patients with Crohn's disease inflammation (Gardet et al., 2010). LRRK2 shows high expression in immune cells including microglia and inhibition of LRRK2 function reduces M1-associated inflammation and PD neurodegeneration (Moehle et al., 2012; Daher et al., 2014, 2015; Russo et al., 2015). Collectively, these studies point toward the importance of LRRK2 function in M1activation responses in PD animal models (Moehle and West, 2015).

Three different missense mutations (A530T, A30P, and E46K) within the open reading frame or duplication or triplication of the wild type $\alpha$-synuclein gene (SNCA, PARK1) are associated with autosomal dominant PD (Polymeropoulos et al., 1997; Kruger et al., 1998; Singleton et al., 2003; Zarranz et al., 2004). Fibrillar forms of $\alpha$-synuclein are a major component of the Lewy bodies in both sporadic and familial PD. $\alpha$-Synuclein, a cytoplasmic protein, can be expressed in microglia and may be involve modulation and pre-sensitization of microglial activation (Barkholt et al., 2012; Roodveldt et al., 2013; Zhang et al., 2017). Most activated microglia in PD patient brains are associated with $\alpha$-synuclein-positive Lewy neurites (Imamura et al., 2003), and there is significant correlation between the expression of M1 activation-associated marker MHC-II and $\alpha$-synuclein deposition in the substantia nigra of PD patients (Croisier et al., 2005). Previous studies by our group and others using in vitro and animal models show that both wild type and mutant $\alpha$-synuclein can modulate microglial activation leading to neuroinflammation. Our previous work shows that $\alpha$-synuclein activates microglia in a dose-dependent manner in cultured cells and an early microglial activation event occurs in mice overexpressing wild type $\alpha$-synuclein (Su et al., 2008). Another study reveals that mutant $\alpha$-synuclein can directly interact with cultured microglia releasing pro-inflammatory substances and mice overexpressing mutant $\alpha$-synuclein exhibit microglial activation at a very early age (Su et al., 2009). In addition, we show that misfolded $\alpha$-synuclein induces microglial activation and the release of pro-inflammatory cytokines in BV2 microglial cells (Beraud et al., 2013). Overexpression of $\alpha$-synuclein in BV2 microglial cells increase pro-inflammatory mediators (TNF- $\alpha$, IL- 6 , nitric oxide, COX-2) and induce a reactive microglial phenotype (Rojanathammanee et al., 2011). Interestingly, TLR4, which is activated by LPS to induce microglial M1-phenotype, is reported to mediate $\alpha$-synuclein-induced microglial phagocytosis, upregulation of pro-inflammatory cytokine expression and ROS generation in primary microglial cultures (Fellner et al., 2013). In addition, $\alpha$-synuclein is reported to play a crucial role in modulating microglial activation states in postnatal brain derived microglial cultures (Austin et al., 2006). Moreover, neuroinflammation with activated microglia and increased pro-inflammatory cytokines (TNF- $\alpha$, IL-1 $\beta$, IFN- $\gamma$ ) precedes $\alpha$-synuclein-mediated neuronal cell death in rats delivered with mutant A53T human $\alpha$-synuclein (Chung et al., 2009). There is a rich literature on the role of $\alpha$-synuclein in the progression of PD by inducing microglia activation and neuroinflammation which is reviewed elsewhere (Zhang et al., 2017).

In addition, genes linked to familial recessive PD including phosphatase and tensin homolog (PTEN)-induced kinase 1 (PINK1, PARK6) and DJ-1 (PARK7) are strongly associated with neuroinflammation. Deletion of PINK1 or DJ-1 causes aberrant expression of genes involved in $\mathrm{p} 38 \mathrm{MAP}$ kinase/NF- $\mathrm{\kappa B}$ signaling pathways that regulate innate immune responses in disease models (Cornejo Castro et al., 2010; Akundi et al., 2011). 


\section{INFLAMMATION IN PD ANIMAL MODELS}

LPS, a bacterial endotoxin from cell wall of Gram-negative bacteria, induces M1-polarization of microglia through activation the pattern recognition TLR4. LPS administration into rodent brains recapitulate certain characteristics of sporadic PD including progressive degeneration of nigrostriatal dopaminergic pathway and motor anomalies. A single injection or 2-week infusion of LPS in the supranigral region in rat brain causes rapid microglia activation followed by dose and time-dependent degeneration of nigrostriatal dopaminergic circuitry (Castano et al., 1998; Gao et al., 2002; Liu, 2006; Dutta et al., 2008). Direct injection of LPS shows dopaminergic neuron loss specifically in SNpc but not in ventral tegmental area which also houses dopaminergic neurons (Kim et al., 2000). This specific neurotoxicity in SNpc may be attributed to the high proportion of microglia in SNpc compared with other brain regions (Lawson et al., 1990), that may trigger inflammatory events leading to the degeneration of nigrostriatal pathway. Moreover, injection of a TLR3 agonist in the substantia nigra of adult rats induces a sustained inflammatory reaction in the substantia nigra (SN) and dorsolateral striatum, and also increases the vulnerability of midbrain dopaminergic neurons to a subsequent neurotoxic trigger (Deleidi et al., 2010).

A transgenic mouse PD model that overexpresses human wild type $\alpha$-synuclein, Thy1-aSyn (line 61) (Chesselet et al., 2012), shows microglial activation as early as 1 month and persists until 14 months of age (Watson et al., 2012). Increased levels of TNF- $\alpha$, TLRs (TLR1, TLR2, TLR4, and TLR8), MHC-II, CD4, and CD8 are observed in Thy1-aSyn mice at different ages. This study also reveals that despite expression of $\alpha$-synuclein globally in the brain only the regions containing cell bodies and axon terminals of nigrostriatal pathway show early inflammatory response. Another transgenic rodent model overexpressing doubly mutated (A53T and A30P) human $\alpha$-synuclein show glial mitochondria alterations (Schmidt et al., 2011). In a PD mouse model that overexpresses human $\alpha$-synuclein by recombinant adeno-associated virus vector, serotype 2 (rAAV2)-mediated transduction in the $\mathrm{SNpc}$, inflammatory responses such as microglial activation and greater infiltration of $\mathrm{B}$ and $\mathrm{T}$ lymphocytes are observed in addition to dopaminergic neurodegeneration (Theodore et al., 2008). These studies show that animal models overexpressing human or mutant $\alpha$-synuclein exhibit microglial activation and neuroinflammation.

MPTP, a meperidine analog byproduct, is a neurotoxin that causes acute and irreversible human parkinsonism (Davis et al., 1979; Langston et al., 1983). MPTP is a lipophilic compound that can actively cross the blood-brain barrier and gets oxidized by monoamine oxidase to the toxic cation, $\mathrm{MPP}^{+}$(1-methyl4-phenylpyridinium) in the glial cells (Langston et al., 1984; Markey et al., 1984). $\mathrm{MPP}^{+}$utilizes the DA transporter (DAT) to get into the dopaminergic neurons. $\mathrm{MPP}^{+}$accumulates in the mitochondria and inhibits the mitochondrial complex I in the electron transport chain (ETC) (Nicklas et al., 1985; Ramsay et al., 1986) resulting in reduced ATP levels and production of ROS (Hasegawa et al., 1990; Chan et al., 1991; Hantraye et al., 1996;
Przedborski et al., 1996; Fabre et al., 1999; Pennathur et al., 1999). In animal models, MPTP induces inflammatory responses that lead to neurodegeneration. MPTP causes microglial activation and an increase in M1-associated pro-inflammatory cytokines such as IL-6, IFN- $\gamma$ and TNF- $\alpha$. The glial response to MPTP is reported to peak before dopaminergic neuron loss (Czlonkowska et al., 1996; Smeyne and Jackson-Lewis, 2005). In support of these findings, it is reported that mice lacking IFN- $\gamma$ or TNF- $\alpha$ signaling show resistance to MPTP-induced neurodegeneration (Sriram et al., 2002; Mount et al., 2007). Mice treated with MPTP show T-cell $\left(\mathrm{CD} 4^{+}\right)$infiltration into the substantia nigra and the MPTP-induced dopaminergic neuron loss is attenuated in T-cell deficient mice suggesting a pro-inflammatory role for T-cells $\left(\mathrm{CD}^{+}\right)$in MPTP neurotoxicity (Brochard et al., 2009). In addition, treatment with anti-inflammatory agents such as minocycline (Du et al., 2001), ibuprofen (Swiatkiewicz et al., 2013), flavonoid pycnogenol (Khan et al., 2013) and peptide carnosine (Tsai et al., 2010) and inhibition of pro-inflammatory mediators (Watanabe et al., 2004; Zhao et al., 2007), reduce inflammation and prevent neurodegeneration in MPTP animal models.

\section{REGULATORS OF MICROGLIAL ACTIVATION STATES}

Microglial activation, astrogliosis and invasion of activated peripheral immune cells trigger deleterious events in the brain that lead to neuronal loss and progression of PD (Hirsch and Hunot, 2009). These observations led to several animal studies and clinical trials to test a variety of established antiinflammatory molecules (see Table 2). Acetylsalicylic acid, a COX-1/COX-2 inhibitor, exhibits neuroprotective effects in in vitro and in MPTP animal models of PD (Teismann and Ferger, 2001). A prospective clinical study shows that consumption of non-aspirin NSAIDs may delay or prevent the onset of PD (Chen et al., 2003). A Cochrane collaboration study which analyzed several prevention trials and observational antiinflammatory studies reveals that while ibuprofen use might reduce the risk of developing $\mathrm{PD}$, there is no existing evidence that supports NSAID use in PD prevention (Rees et al., 2011). A clinical study in PD cases shows an association between use of ibuprofen and lesser PD risk. However, this association is not shared by other NSAIDs studied (Gao et al., 2011). Similarly, minocycline, a tetracycline antibiotic that showed promising anti-inflammatory properties in PD animal models (Du et al., 2001; He et al., 2001; Wu et al., 2002), did not provide any symptomatic improvement in PD patients (Ninds Net-Pd Investigators, 2008). See Table 2 for the list of anti-inflammatory agents studied in PD. Hence, NSAID use appears to provide benefits in PD susceptibility in some cases (Wahner et al., 2007; Samii et al., 2009; Gagne and Power, 2010; Steurer, 2011), however, this beneficial effect of NSAIDs were not replicated in several other studies (Shaunak et al., 1995; Bornebroek et al., 2007; Samii et al., 2009; Becker et al., 2011). One study even suggests that anti-inflammatory drug treatment may be detrimental if given at the later stage of the 
TABLE 2 | NSAIDs and other anti-inflammatory agents in PD models and clinical trials.

\begin{tabular}{|c|c|c|c|c|}
\hline Molecule & PD model & Mechanism & Response & Reference \\
\hline \multirow[t]{2}{*}{ Ibuprofen } & Mouse MPTP & Anti-inflammatory & Prevent striatal-TH loss & Swiatkiewicz et al., 2013 \\
\hline & Clinical trial & Anti-inflammatory & Reduce PD risk & Gao et al., 2011 \\
\hline Acetylsalicylic acid & Mouse MPTP & COX-1/COX-2 inhibitor & $\begin{array}{l}\text { Attenuate loss of nigral DA-neurons, striatal } \\
\text { dopamine and locomotor activity }\end{array}$ & Teismann and Ferger, 2001 \\
\hline \multirow[t]{2}{*}{ NSAIDs } & Clinical trials & Anti-inflammatory & Delay or prevent onset of PD & $\begin{array}{l}\text { Chen et al., 2003; Wahner et al., 2007; } \\
\text { Samii et al., 2009; Gagne and Power, } \\
\text { 2010; Steurer, 2011 }\end{array}$ \\
\hline & Clinical trials & Anti-inflammatory & $\begin{array}{l}\text { Exacerbate PD symptoms/Does NOT } \\
\text { improve PD risk }\end{array}$ & $\begin{array}{l}\text { Shaunak et al., 1995; Bornebroek } \\
\text { et al., 2007; Samii et al., 2009; Becker } \\
\text { et al., } 2011\end{array}$ \\
\hline \multirow[t]{2}{*}{ Minocycline } & $\begin{array}{l}\text { Mouse MPTP Mouse } \\
6-O H D A\end{array}$ & $\begin{array}{l}\text { Anti-inflammatory } \\
\text { Anti-inflammatory }\end{array}$ & $\begin{array}{l}\text { Attenuate loss of nigral DA-neurons and } \\
\text { striatal dopamine Protect TH-positive cells }\end{array}$ & $\begin{array}{l}\text { Du et al., 2001; Wu et al., 2002; He } \\
\text { et al., } 2001\end{array}$ \\
\hline & Clinical trial & Anti-inflammatory & Does NOT improve PD symptoms & Ninds Net-Pd Investigators, 2008 \\
\hline
\end{tabular}

COX, cyclooxygenase; DA, dopamine; MPTP, 1-methyl-4-phenyl-1,2,3,6-tetrahydropyridine; NSAIDs, non-steroidal anti-inflammatory drugs; TH, tyrosine hydroxylase.

disease (Keller et al., 2011). This therapeutic approach aiming to counteract general neuroinflammation has failed in several disease therapies as reviewed elsewhere (Pena-Altamira et al., 2016). Collectively, these studies indicate that the non-specific inflammatory blockade is unlikely to be beneficial for the disease treatment. Concurrently, the data on the dual role of microglial activation has led to the emergence of the novel therapeutic strategy in other inflammatory diseases such as rheumatoid arthritis, ankylosing spondylitis, and multiple sclerosis (MS) (Rau, 2002; Braun et al., 2007; Wilms et al., 2010; Noda et al., 2013). This approach of the M1 to the M2 phenotype shift might be beneficial in neuroprotection compared to completely blocking microglial activation through anti-inflammatory drugs. Hence, a more reasonable approach of more specific treatment related to the M1/M2 activation stage by inhibiting the M1 responses and/or promoting the shift of M1 to M2 phenotypic responses is necessary in $\mathrm{PD}$.

\section{Targeting M1 Polarization State: Inhibition of Pro-inflammatory M1 Phenotype}

M1 activation of microglia results in a pro-inflammatory and pro-killing output. To inhibit the pro-inflammatory damage through M1 activation of microglia, its downstream signaling pathways could be targeted. M1 phenotype is induced by IFN- $\gamma$ via the JAK/STAT signaling pathway and targeting this pathway may arrest M1 activation. In fact, studies show that inhibition of the JAK/STAT pathway leads to suppression of the downstream M1-associated genes in several disease models including experimental allergic encephalomyelitis models and myeloproliferative neoplasms (Liu et al., 2014; Mascarenhas et al., 2014). Another approach to suppress M1 activation would be to target the pro-inflammatory cytokines such as TNF- $\alpha$, IL- $1 \beta$ and IFN- $\gamma$, and decrease its ability to interact with its receptors on other cell types. TNF has been targeted through different approaches in PD animal models to suppress M1-associated toxicity. A single injection of lentivirus-expressing dominant negative TNF (DN-TNF) into the rat substantia nigra concomitantly with 6-hydroxydopamine (6-OHDA) lesion in the striatum attenuates dopaminergic neuron loss and behavioral anomalies in rats (McCoy et al., 2008). In another study intended to examine the role of TNF in delayed and progressive neurodegeneration model, rats administered with DN-TNF in the substantia nigra 2 weeks after the 6-OHDA lesion show no further dopaminergic neuron loss even after 5 weeks of 6-OHDA suggesting that TNF is an essential mediator of inflammation and hence a promising therapeutic target in PD (Harms et al., 2011). In addition, adeno-associated virus (AAV)mediated transduction of dopaminergic neurons with human ras homolog enriched in brain with $\mathrm{S} 16 \mathrm{H}$ mutation, [hRheb $(\mathrm{S} 16 \mathrm{H})]$, attenuates nigrostriatal toxicity in 6-OHDA rat model of PD (Kim et al., 2011, 2012). This protective effect is mediated by the production of cAMP response element-binding protein ( $\mathrm{p}$ CREB), glial cell line-derived neurotrophic factor (GDNF), and brain-derived neurotrophic factor (BDNF) in unilateral $\mathrm{MPP}^{+}$ neurotoxin PD model (Nam et al., 2015).

PPARs are actively involved in microglial activation and inflammatory pathways. PPAR agonists are postulated to be beneficial for $\mathrm{PD}$ and other neurodegenerative diseases (Agarwal et al., 2017). The administration of a PPAR $\gamma$ agonist, rosiglitazone, arrests degeneration in both striatum and $\mathrm{SNpc}$ by decreasing TNF- $\alpha$ production and modulating microglial polarization in MPTPp (MPTP + probenecid) progressive mouse model of PD (Carta et al., 2011; Pisanu et al., 2014). Pioglitazone, a PPAR $\gamma$ agonist, prevents tyrosine hydroxylase (TH)-positive neuron loss in substantia nigra and partially averts striatal DA loss in MPTP mice model of PD. Pioglitazone treatment decreases microglial activation, iNOS production and nitric oxide-mediated toxicity in both striatum and substantia nigra (Dehmer et al., 2004). However, a recent clinical trial concluded that pioglitazone did not modify progression in early PD (Ninds Exploratory Trials in Parkinson Disease (Net-Pd) Fs-Zone Investigators, 2015). On the other hand, pioglitazone and rosiglitazone are currently being evaluated in clinical trials for its potential to reduce progression of $\mathrm{AD}$. In 
addition, treatment of LPS/IFN- $\gamma$-activated neuronal and glial cultures with a PPAR $\gamma$ endogenous ligand, 15-deoxy- $\triangle^{12,14}$ prostaglandin $\mathrm{J}_{2}$, inhibits pro-inflammatory response through the CD200-CD200R1 dependent mechanism (Dentesano et al., 2014). Unpublished data from our group show that administration of a PPAR agonist protects dopaminergic neurons in SNpc and neurites in striatum in MPTP mouse model of PD. This PPAR agonist reduces LPS-induced M1associated pro-inflammatory cytokine IL-1 $\beta$ in BV2 cells and primary astrocytes in a PPAR $\alpha$-independent manner. Thus, PPAR agonists are potential molecules for curing PD through their property to inhibit M1 microglia-induced neuroinflammation.

Alterations in expression of cannabinoid receptors and endocannabinoid concentrations are illustrated in PD pathogenesis (Garcia et al., 2015). The endocannabinoid system includes the cannabinoid receptors $\mathrm{CB} 1$ and $\mathrm{CB} 2$, the endogenous ligands (anandamide and 2-arachidonoylglycerol, $2-\mathrm{AG})$, and their regulatory enzymes. $\mathrm{CB} 1$ receptors are abundant in neurons whereas $\mathrm{CB} 2$ receptors are most specifically expressed in glia (Onaivi, 2006; Lanciego et al., 2011; FernandezSuarez et al., 2014; Sierra et al., 2015). The expression of CB2 receptors significantly increases during microglial activation (Maresz et al., 2005; Yiangou et al., 2006) and CB2 receptors are reported to be localized in substantia nigra, and significantly downregulated in PD patients (Garcia et al., 2015). A naturally occurring $\mathrm{CB} 2$ receptor agonist, $\beta$-caryophyllene (BCP), prevented nigral DA-neuron and striatal-TH loss, reduced glial activation and inhibited pro-inflammatory cytokines in rat rotenone model of PD (Javed et al., 2016). Another study shows that a non-selective cannabinoid agonist protects loss of DA-neurons in the substantia nigra and DA in the striatum of MPTP intoxicated mice. In addition, this cannabinoid agonist also reduces MPTP-induced motor deficits and microglial activation (Price et al., 2009). Modification of the endocannabinoid system, to reduce pro-inflammatory toxicity, may provide a novel therapeutic avenue for $\mathrm{PD}$ treatment.

Tanshinone-I, a bioactive flavonoid, reduces the production of M1-pro-inflammatory mediators (nitric oxide, TNF- $\alpha$, IL-6 and IL-1 $\beta$ ) and, inhibits G-CSF and NF- $\kappa B$ expression after LPS-induced inflammation in BV2 microglial cell lines. In the MPTP mouse model of PD, Tanshinone-I prevents dopaminergic neurotoxicity, improves motor deficits and striatal neurotransmitters (Wang et al., 2015). Ghrelin, a stomachderived endogenous ligand for growth hormone secretagogue receptor 1a (GHS-R1a), prevents loss of nigral dopaminergic neurons and striatal neurites, and improves motor performance in MPTP mouse model of PD. Ghrelin reduces toxicant-induced microglial activation, production of pro-inflammatory cytokines (IL-1 $\beta$, TNF- $\alpha$ ) and iNOS levels in MPTP mice (Jiang et al., 2008; Moon et al., 2009). Piperine, a naturally occurring bioactive molecule, attenuates the loss of $\mathrm{TH}$-positive neurons in the substantia nigra and MPTP-induced motor anomalies. In addition, piperine decreases MPTP-induced microglial activation, pro-inflammatory IL- $1 \beta$ expression and apoptosis in these mice (Yang et al., 2015). See Table 3 for the summary of other potential molecules that act by inhibiting M1 activation in PD models.

\section{Targeting M2 Polarization State}

The molecules with the capability to activate the antiinflammatory M2 phenotype or promote the transition of proinflammatory M1 phenotype to anti-inflammatory M2 could be useful in the treatment of PD. Anti-inflammatory molecules such as IL-10 and beta interferons produce neuroprotection by altering the M1 and M2 balance. Cerebral infusion of AAVexpressing human IL-10 in a MPTP mouse model of PD decreases the expression of pro-inflammatory iNOS and importantly enhances the levels of anti-inflammatory mediators including IFN- $\gamma$ and transforming growth factor- $\beta$ (TGF- $\beta$ ). Infusion of AAV-expressing human IL-10 prevents the loss of striatal DA and reduces $\mathrm{TH}$ transcriptome levels suggesting neuroprotection in MPTP intoxicated mice (Schwenkgrub et al., 2013; JoniecMaciejak et al., 2014).

Treatment with pioglitazone, a PPAR $\gamma$ agonist, causes a phenotypic conversion of microglia from the pro-inflammatory M1 state to the anti-inflammatory M2 state. This conversion is strongly linked to increase in phagocytosis of misfolded protein deposits resulting in the reduction of amyloid levels and an associated reversal of contextual memory deficits in AD mice (Mandrekar-Colucci et al., 2012). As mentioned before, pioglitazone treatment decreases microglial activation, iNOS production and NO-mediated nigrostriatal toxicity in MPTP mouse model (Dehmer et al., 2004).

The endocannabinoid system is implicated in PD pathogenesis (Garcia et al., 2015). In a chronic MPTPp model of PD, the administration of an inhibitor that prevents degradation of $2-\mathrm{AG}$ (JZL184), an endocannabinoid ligand, prevents MPTPp-induced motor impairment and protects the nigrostriatal pathway (Fernandez-Suarez et al., 2014). MPTPp mice treated with JZL184 exhibits microglial phenotypic changes and restorative microglial activation along with increased TGF- $\beta$ and GDNF levels.

Glatiramer acetate is a Food and Drug Administration (FDA) approved drug for MS treatment (English and Aloi, 2015) and its neuroprotective effect is mediated by activation of the microglial M2 phenotype (Giunti et al., 2014). Glatiramer acetate protects dopaminergic neurons in a MPTP mouse model by helping the recruitment of $\mathrm{T}$ lymphocytes in the $\mathrm{SN}$, while inhibiting microglial activation and upregulation of GDNF expression (Benner et al., 2004; Burger et al., 2009). Glatiramer acetate also exhibits neuroprotection in Alzheimer's disease animal models where its treatment induces microglial co-localization with amyloid fibrils and a switch in microglial phenotype that produces insulin like growth factor 1 (Butovsky et al., 2006). Dimethyl fumarate (DMF), an approved drug for MS treatment, protects against the depletion of striatal DA and its transporters and, reduces MPTP-induced increase in IL- $1 \beta$ and COX-2 activity in MPTP mouse model of PD. DMF also modulates microglial activation states and restores nerve growth factor levels to provide neuroprotection in MPTP-intoxicated mice (Campolo et al., 2017). Other molecules that are reported to possess neuroprotective properties by inducing M2 microglial activation are listed in Table 3. 
TABLE 3 | Molecules targeting microglia activation in PD animal models and clinical trials.

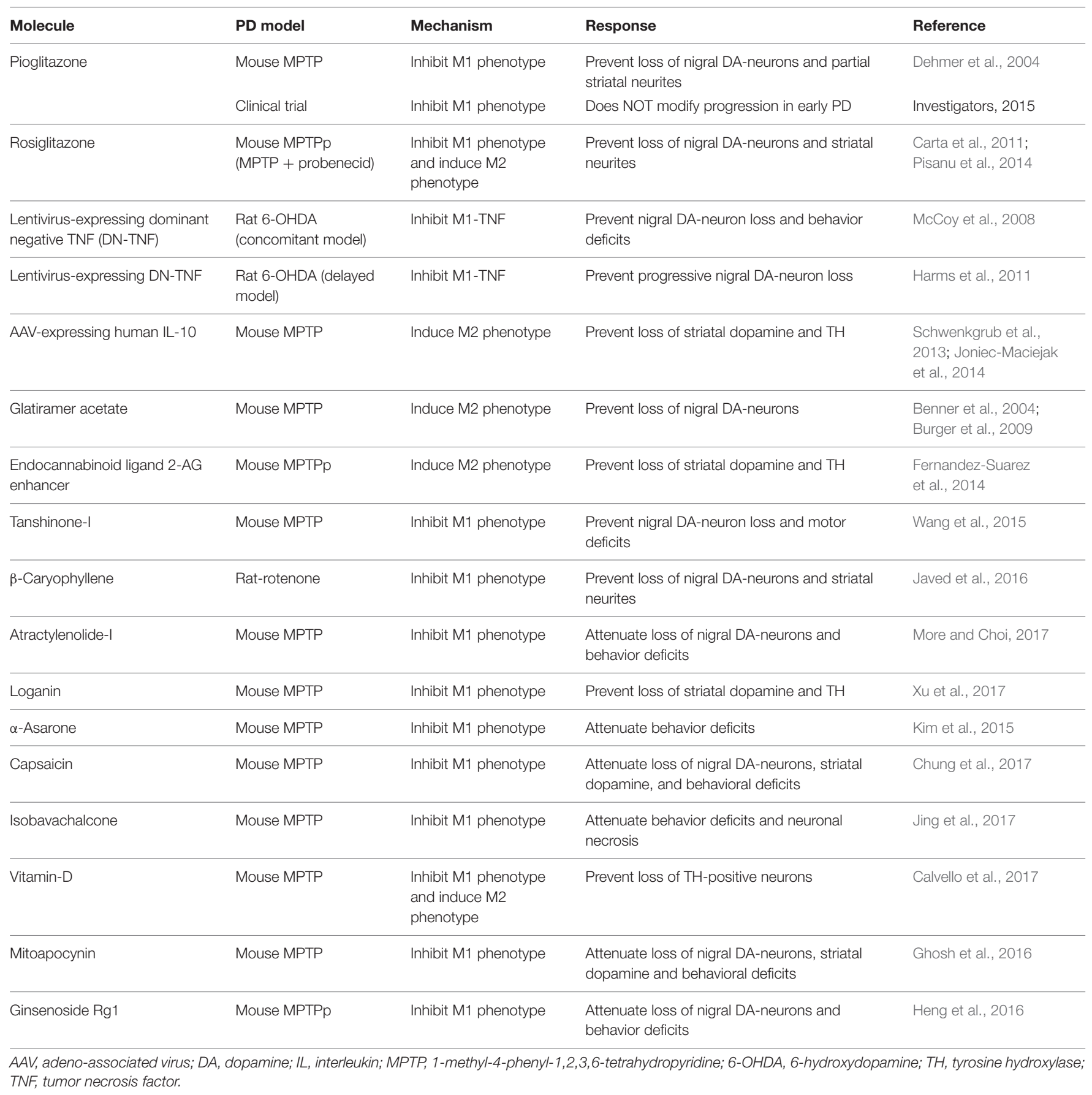

\section{NOVEL MICROGLIAL TARGETS}

Other novel potential microglial targets for immunomodulation are reviewed elsewhere (Pena-Altamira et al., 2016). These approaches include the following targets: (1) $5^{\prime}$ adenosine monophosphate-activated protein kinase (AMPK): a critical enzyme in cellular energy homeostasis, (2) microglia-produced high-mobility group box-1 (HMGB1): an early released pro-inflammatory cytokine, (3) glycogen synthase kinase$3 \beta$ (GSK3 $\beta$ ): an enzyme that mediates microglial migration and inflammation-induced neurotoxicity, and (4) histone deacetylases (HDACs).

\section{CONCLUDING REMARKS AND FUTURE DIRECTIONS}

The critical role of microglia in most neurodegenerative pathologies including PD is increasingly documented through many studies. Until recently, microglial activation in pathological 
conditions was considered to be detrimental to neuronal survival in the substantia nigra of PD brains. Recent findings highlight the crucial physiological and neuroprotective role of microglia and other glial cells in neuropathological conditions. Studies on anti-inflammatory treatments targeting neuroinflammation in PD and other diseases by delaying or blocking microglial activation failed in many trials due to the lack of a specific treatment approach, possibly the stage of disease and an incorrect understanding of mechanisms underlying microglial activation. With the updated knowledge on different microglial activation states, drugs that can shift microglia from a pro-inflammatory

\section{REFERENCES}

Agarwal, S., Yadav, A., and Chaturvedi, R. K. (2017). Peroxisome proliferatoractivated receptors (PPARs) as therapeutic target in neurodegenerative disorders. Biochem. Biophys. Res. Commun. 483, 1166-1177. doi: 10.1016/j.bbrc. 2016.08.043

Akundi, R. S., Huang, Z., Eason, J., Pandya, J. D., Zhi, L., Cass, W. A., et al. (2011). Increased mitochondrial calcium sensitivity and abnormal expression of innate immunity genes precede dopaminergic defects in Pink1-deficient mice. PLoS ONE 6:e16038. doi: 10.1371/journal.pone.0016038

Alliot, F., Godin, I., and Pessac, B. (1999). Microglia derive from progenitors, originating from the yolk sac, and which proliferate in the brain. Brain Res. Dev. Brain Res. 117, 145-152. doi: 10.1016/S0165-3806(99)00113-3

Austin, S. A., Floden, A. M., Murphy, E. J., and Combs, C. K. (2006). Alphasynuclein expression modulates microglial activation phenotype. J. Neurosci. 26, 10558-10563. doi: 10.1523/JNEUROSCI.1799-06.2006

Barkholt, P., Sanchez-Guajardo, V., Kirik, D., and Romero-Ramos, M. (2012). Long-term polarization of microglia upon alpha-synuclein overexpression in nonhuman primates. Neuroscience 208, 85-96. doi: 10.1016/j.neuroscience. 2012.02.004

Barrett, J. C., Hansoul, S., Nicolae, D. L., Cho, J. H., Duerr, R. H., Rioux, J. D., et al. (2008). Genome-wide association defines more than 30 distinct susceptibility loci for Crohn's disease. Nat. Genet. 40, 955-962. doi: 10.1038/ng.175

Becker, C., Jick, S. S., and Meier, C. R. (2011). NSAID use and risk of Parkinson disease: a population-based case-control study. Eur. J. Neurol. 18, 1336-1342. doi: 10.1111/j.1468-1331.2011.03399.x

Benarroch, E. E. (2013). Microglia: multiple roles in surveillance, circuit shaping, and response to injury. Neurology 81, 1079-1088. doi: 10.1212/WNL. 0b013e3182a4a577

Benner, E. J., Mosley, R. L., Destache, C. J., Lewis, T. B., Jackson-Lewis, V., Gorantla, S., et al. (2004). Therapeutic immunization protects dopaminergic neurons in a mouse model of Parkinson's disease. Proc. Natl. Acad. Sci. U.S.A. 101, 9435-9440. doi: 10.1073/pnas.0400569101

Beraud, D., Hathaway, H. A., Trecki, J., Chasovskikh, S., Johnson, D. A., Johnson, J. A., et al. (2013). Microglial activation and antioxidant responses induced by the Parkinson's disease protein alpha-synuclein. J. Neuroimmune Pharmacol. 8, 94-117. doi: 10.1007/s11481-012-9401-0

Bjarkam, C. R., and Sorensen, J. C. (2004). Therapeutic strategies for neurodegenerative disorders: emerging clues from Parkinson's disease. Biol. Psychiatry 56, 213-216. doi: 10.1016/j.biopsych.2003.12.025

Block, M. L., Zecca, L., and Hong, J. S. (2007). Microglia-mediated neurotoxicity: uncovering the molecular mechanisms. Nat. Rev. Neurosci. 8, 57-69. doi: $10.1038 /$ nrn2038

Boche, D., Perry, V. H., and Nicoll, J. A. (2013). Review: activation patterns of microglia and their identification in the human brain. Neuropathol. Appl. Neurobiol. 39, 3-18. doi: 10.1111/nan.12011

Boka, G., Anglade, P., Wallach, D., Javoy-Agid, F., Agid, Y., and Hirsch, E. C. (1994). Immunocytochemical analysis of tumor necrosis factor and its receptors in Parkinson's disease. Neurosci. Lett. 172, 151-154. doi: 10.1016/0304-3940(94) 90684-X

Bornebroek, M., de Lau, L. M., Haag, M. D., Koudstaal, P. J., Hofman, A., Stricker, B. H., et al. (2007). Nonsteroidal anti-inflammatory drugs and the risk of Parkinson disease. Neuroepidemiology 28, 193-196. doi: 10.1159/000108110
M1 state to anti-inflammatory M2 state could be beneficial for $\mathrm{PD}$. The M1 and M2 microglial phenotypes probably need further characterization, particularly in PD pathological conditions for better therapeutic targeting. We support targeting of microglial cells by modulating their activation states as a novel therapeutic approach for PD.

\section{AUTHOR CONTRIBUTIONS}

\section{HF conceived of the project, SS and HF wrote the manuscript.}

Braak, H., Rub, U., Gai, W. P., and Del Tredici, K. (2003). Idiopathic Parkinson's disease: possible routes by which vulnerable neuronal types may be subject to neuroinvasion by an unknown pathogen. J. Neural Transm. 110, 517-536. doi: 10.1007/s00702-002-0808-2

Braun, J., McHugh, N., Singh, A., Wajdula, J. S., and Sato, R. (2007). Improvement in patient-reported outcomes for patients with ankylosing spondylitis treated with etanercept $50 \mathrm{mg}$ once-weekly and $25 \mathrm{mg}$ twice-weekly. Rheumatology 46, 999-1004. doi: 10.1093/rheumatology/kem069

Brochard, V., Combadiere, B., Prigent, A., Laouar, Y., Perrin, A., Beray-Berthat, V., et al. (2009). Infiltration of CD4+ lymphocytes into the brain contributes to neurodegeneration in a mouse model of Parkinson disease. J. Clin. Invest. 119, 182-192. doi: 10.1172/JCI36470

Bruce-Keller, A. J. (1999). Microglial-neuronal interactions in synaptic damage and recovery. J. Neurosci. Res. 58, 191-201. doi: 10.1002/(SICI)10974547(19991001)58:1<191::AID-JNR17>3.0.CO;2-E

Burger, D., Molnarfi, N., Weber, M. S., Brandt, K. J., Benkhoucha, M., Gruaz, L., et al. (2009). Glatiramer acetate increases IL-1 receptor antagonist but decreases $\mathrm{T}$ cell-induced IL-1beta in human monocytes and multiple sclerosis. Proc. Natl. Acad. Sci. U.S.A. 106, 4355-4359. doi: 10.1073/pnas.081 2183106

Butovsky, O., Koronyo-Hamaoui, M., Kunis, G., Ophir, E., Landa, G., Cohen, H., et al. (2006). Glatiramer acetate fights against Alzheimer's disease by inducing dendritic-like microglia expressing insulin-like growth factor 1. Proc. Natl. Acad. Sci. U.S.A. 103, 11784-11789. doi: 10.1073/pnas.0604681103

Calvello, R., Cianciulli, A., Nicolardi, G., De Nuccio, F., Giannotti, L., Salvatore, R., et al. (2017). Vitamin D treatment attenuates neuroinflammation and dopaminergic neurodegeneration in an animal model of Parkinson's disease, shifting M1 to M2 microglia responses. J. Neuroimmune Pharmacol. 12, 327-339. doi: 10.1007/s11481-016-9720-7

Campolo, M., Casili, G., Biundo, F., Crupi, R., Cordaro, M., Cuzzocrea, S., et al. (2017). The neuroprotective effect of dimethyl fumarate in an MPTP-mouse model of Parkinson's disease: involvement of reactive oxygen species/nuclear factor-kappaB/nuclear transcription factor related to NF-E2. Antioxid. Redox Signal. doi: 10.1089/ars.2016.6800 [Epub ahead of print].

Carta, A. R., Frau, L., Pisanu, A., Wardas, J., Spiga, S., and Carboni, E. (2011). Rosiglitazone decreases peroxisome proliferator receptor-gamma levels in microglia and inhibits TNF-alpha production: new evidences on neuroprotection in a progressive Parkinson's disease model. Neuroscience 194, 250-261. doi: 10.1016/j.neuroscience.2011.07.046

Castano, A., Herrera, A. J., Cano, J., and Machado, A. (1998). Lipopolysaccharide intranigral injection induces inflammatory reaction and damage in nigrostriatal dopaminergic system. J. Neurochem. 70, 1584-1592. doi: 10.1046/j.1471-4159. 1998.70041584.x

Chan, P., DeLanney, L. E., Irwin, I., Langston, J. W., and Di Monte, D. (1991). Rapid ATP loss caused by 1-methyl-4-phenyl-1,2,3,6-tetrahydropyridine in mouse brain. J. Neurochem. 57, 348-351. doi: 10.1111/j.1471-4159.1991. tb02134.x

Chandra, G., Roy, A., Rangasamy, S. B., and Pahan, K. (2017). Induction of adaptive immunity leads to nigrostriatal disease progression in MPTP mouse model of Parkinson's disease. J. Immunol. doi: 10.4049/jimmunol.1700149 [Epub ahead of print].

Chen, H., Zhang, S. M., Hernan, M. A., Schwarzschild, M. A., Willett, W. C., Colditz, G. A., et al. (2003). Nonsteroidal anti-inflammatory drugs and the risk 
of Parkinson disease. Arch. Neurol. 60, 1059-1064. doi: 10.1001/archneur.60.8. 1059

Chen, Y., Qi, B., Xu, W., Ma, B., Li, L., Chen, Q., et al. (2015). Clinical correlation of peripheral CD4+cell subsets, their imbalance and Parkinson's disease. Mol. Med. Rep. 12, 6105-6111. doi: 10.3892/mmr.2015.4136

Chesselet, M. F., Richter, F., Zhu, C., Magen, I., Watson, M. B., and Subramaniam, S. R. (2012). A progressive mouse model of Parkinson's disease: the Thy1aSyn ("Line 61") mice. Neurotherapeutics 9, 297-314. doi: 10.1007/s13311-0120104-2

Chhor, V., Le Charpentier, T., Lebon, S., Ore, M. V., Celador, I. L., Josserand, J., et al. (2013). Characterization of phenotype markers and neuronotoxic potential of polarised primary microglia in vitro. Brain Behav. Immun. 32, 70-85. doi: 10.1016/j.bbi.2013.02.005

Chung, C. Y., Koprich, J. B., Siddiqi, H., and Isacson, O. (2009). Dynamic changes in presynaptic and axonal transport proteins combined with striatal neuroinflammation precede dopaminergic neuronal loss in a rat model of AAV alpha-synucleinopathy. J. Neurosci. 29, 3365-3373. doi: 10.1523/JNEUROSCI. 5427-08.2009

Chung, Y. C., Baek, J. Y., Kim, S. R., Ko, H. W., Bok, E., Shin, W. H., et al. (2017). Capsaicin prevents degeneration of dopamine neurons by inhibiting glial activation and oxidative stress in the MPTP model of Parkinson's disease. Exp. Mol. Med. 49, e298. doi: 10.1038/emm.2016.159

Conrad, A. T., and Dittel, B. N. (2011). Taming of macrophage and microglial cell activation by microRNA-124. Cell Res. 21, 213-216. doi: 10.1038/cr.2011.9

Cornejo Castro, E. M., Waak, J., Weber, S. S., Fiesel, F. C., Oberhettinger, P., Schutz, M., et al. (2010). Parkinson's disease-associated DJ-1 modulates innate immunity signaling in Caenorhabditis elegans. J. Neural Transm. 117, 599-604. doi: 10.1007/s00702-010-0397-4

Croisier, E., Moran, L. B., Dexter, D. T., Pearce, R. K., and Graeber, M. B. (2005). Microglial inflammation in the parkinsonian substantia nigra: relationship to alpha-synuclein deposition. J. Neuroinflammation 2, 14.

Czlonkowska, A., Kohutnicka, M., Kurkowska-Jastrzebska, I., and Czlonkowski, A. (1996). Microglial reaction in MPTP (1-methyl-4phenyl-1,2,3,6-tetrahydropyridine) induced Parkinson's disease mice model. Neurodegeneration 5, 137-143. doi: 10.1006/neur.1996.0020

Daher, J. P., Abdelmotilib, H. A., Hu, X., Volpicelli-Daley, L. A., Moehle, M. S., Fraser, K. B., et al. (2015). Leucine-rich repeat kinase 2 (LRRK2) Pharmacological inhibition abates alpha-synuclein gene-induced neurodegeneration. J. Biol. Chem. 290, 19433-19444. doi: 10.1074/jbc.M115.660001

Daher, J. P., Volpicelli-Daley, L. A., Blackburn, J. P., Moehle, M. S., and West, A. B. (2014). Abrogation of alpha-synuclein-mediated dopaminergic neurodegeneration in LRRK2-deficient rats. Proc. Natl. Acad. Sci. U.S.A. 111, 9289-9294. doi: 10.1073/pnas.1403215111

Davalos, D., Grutzendler, J., Yang, G., Kim, J. V., Zuo, Y., Jung, S., et al. (2005). ATP mediates rapid microglial response to local brain injury in vivo. Nat. Neurosci. 8, 752-758. doi: $10.1038 / \mathrm{nn} 1472$

Davis, G. C., Williams, A. C., Markey, S. P., Ebert, M. H., Caine, E. D., Reichert, C. M., et al. (1979). Chronic Parkinsonism secondary to intravenous injection of meperidine analogues. Psychiatry Res. 1, 249-254. doi: 10.1016/0165-1781(79) 90006-4

Dehmer, T., Heneka, M. T., Sastre, M., Dichgans, J., and Schulz, J. B. (2004). Protection by pioglitazone in the MPTP model of Parkinson's disease correlates with I kappa B alpha induction and block of NF kappa B and iNOS activation. J. Neurochem. 88, 494-501. doi: 10.1046/j.1471-4159.2003. 02210. $\mathrm{x}$

Deleidi, M., Hallett, P. J., Koprich, J. B., Chung, C. Y., and Isacson, O. (2010). The Toll-like receptor-3 agonist polyinosinic: polycytidylic acid triggers nigrostriatal dopaminergic degeneration. J. Neurosci. 30, 16091-16101. doi: 10.1523/JNEUROSCI.2400-10.2010

Dentesano, G., Serratosa, J., Tusell, J. M., Ramon, P., Valente, T., Saura, J., et al. (2014). CD200R1 and CD200 expression are regulated by PPARgamma in activated glial cells. Glia 62, 982-998. doi: 10.1002/glia. 22656

Du, Y., Ma, Z., Lin, S., Dodel, R. C., Gao, F., Bales, K. R., et al. (2001). Minocycline prevents nigrostriatal dopaminergic neurodegeneration in the MPTP model of Parkinson's disease. Proc. Natl. Acad. Sci. U.S.A. 98, 14669-14674. doi: 10.1073/ pnas. 251341998
Dutta, G., Zhang, P., and Liu, B. (2008). The lipopolysaccharide Parkinson's disease animal model: mechanistic studies and drug discovery. Fundam. Clin. Pharmacol. 22, 453-464. doi: 10.1111/j.1472-8206.2008.00616.x

Dzamko, N., Gysbers, A., Perera, G., Bahar, A., Shankar, A., Gao, J., et al. (2017). Toll-like receptor 2 is increased in neurons in Parkinson's disease brain and may contribute to alpha-synuclein pathology. Acta Neuropathol. 133, 303-319. doi: 10.1007/s00401-016-1648-8

Dzamko, N., Rowe, D. B., and Halliday, G. M. (2016). Increased peripheral inflammation in asymptomatic leucine-rich repeat kinase 2 mutation carriers. Mov. Disord. 31, 889-897. doi: 10.1002/mds.26529

Edison, P., Ahmed, I., Fan, Z., Hinz, R., Gelosa, G., Ray Chaudhuri, K., et al. (2013). Microglia, amyloid, and glucose metabolism in Parkinson's disease with and without dementia. Neuropsychopharmacology 38, 938-949. doi: 10.1038/npp. 2012.255

English, C., and Aloi, J. J. (2015). New FDA-approved disease-modifying therapies for multiple sclerosis. Clin. Ther. 37, 691-715. doi: 10.1016/j.clinthera.2015. 03.001

Fabre, E., Monserrat, J., Herrero, A., Barja, G., and Leret, M. L. (1999). Effect of MPTP on brain mitochondrial $\mathrm{H} 2 \mathrm{O} 2$ and ATP production and on dopamine and DOPAC in the striatum. J. Physiol. Biochem. 55, 325-331.

Fellner, L., Irschick, R., Schanda, K., Reindl, M., Klimaschewski, L., Poewe, W., et al. (2013). Toll-like receptor 4 is required for alpha-synuclein dependent activation of microglia and astroglia. Glia 61, 349-360. doi: 10.1002/glia.22437

Fernandez-Suarez, D., Celorrio, M., Riezu-Boj, J. I., Ugarte, A., Pacheco, R., Gonzalez, H., et al. (2014). Monoacylglycerol lipase inhibitor JZL184 is neuroprotective and alters glial cell phenotype in the chronic MPTP mouse model. Neurobiol. Aging 35, 2603-2616. doi: 10.1016/j.neurobiolaging.2014. 05.021

Franco, R., and Fernandez-Suarez, D. (2015). Alternatively activated microglia and macrophages in the central nervous system. Prog. Neurobiol. 131, 65-86. doi: 10.1016/j.pneurobio.2015.05.003

Frank, M. G., Barrientos, R. M., Biedenkapp, J. C., Rudy, J. W., Watkins, L. R., and Maier, S. F. (2006). mRNA up-regulation of MHC II and pivotal proinflammatory genes in normal brain aging. Neurobiol. Aging 27, 717-722. doi: 10.1016/j.neurobiolaging.2005.03.013

Freilich, R. W., Woodbury, M. E., and Ikezu, T. (2013). Integrated expression profiles of mRNA and miRNA in polarized primary murine microglia. PLoS ONE 8:e79416. doi: 10.1371/journal.pone.0079416

Funk, N., Wieghofer, P., Grimm, S., Schaefer, R., Buhring, H. J., Gasser, T., et al. (2013). Characterization of peripheral hematopoietic stem cells and monocytes in Parkinson's disease. Mov. Disord. 28, 392-395. doi: 10.1002/mds. 25300

Gagne, J. J., and Power, M. C. (2010). Anti-inflammatory drugs and risk of Parkinson disease: a meta-analysis. Neurology 74, 995-1002. doi: 10.1212/WNL. $0 \mathrm{~b} 013 \mathrm{e} 3181 \mathrm{~d} 5 \mathrm{a} 4 \mathrm{a} 3$

Gao, H. M., Jiang, J., Wilson, B., Zhang, W., Hong, J. S., and Liu, B. (2002). Microglial activation-mediated delayed and progressive degeneration of rat nigral dopaminergic neurons: relevance to Parkinson's disease. J. Neurochem. 81, 1285-1297. doi: 10.1046/j.1471-4159.2002.00928.x

Gao, X., Chen, H., Schwarzschild, M. A., and Ascherio, A. (2011). Use of ibuprofen and risk of Parkinson disease. Neurology 76, 863-869. doi: 10.1212/WNL. 0b013e31820f2d79

Garcia, M. C., Cinquina, V., Palomo-Garo, C., Rabano, A., and FernandezRuiz, J. (2015). Identification of $\mathrm{CB}(2)$ receptors in human nigral neurons that degenerate in Parkinson's disease. Neurosci. Lett. 587, 1-4. doi: 10.1016/j.neulet. 2014.12.003

Gardet, A., Benita, Y., Li, C., Sands, B. E., Ballester, I., Stevens, C., et al. (2010). LRRK2 is involved in the IFN-gamma response and host response to pathogens. J. Immunol. 185, 5577-5585. doi: 10.4049/jimmunol.1000548

Gehrmann, J., Matsumoto, Y., and Kreutzberg, G. W. (1995). Microglia: intrinsic immuneffector cell of the brain. Brain Res. Brain Res. Rev. 20, 269-287. doi: 10.1016/0165-0173(94)00015-H

Gerhard, A., Pavese, N., Hotton, G., Turkheimer, F., Es, M., Hammers, A., et al. (2006). In vivo imaging of microglial activation with [11C](R)-PK11195 PET in idiopathic Parkinson's disease. Neurobiol. Dis. 21, 404-412. doi: 10.1016/j.nbd. 2005.08.002

Ghosh, A., Langley, M. R., Harischandra, D. S., Neal, M. L., Jin, H., Anantharam, V., et al. (2016). Mitoapocynin treatment protects against neuroinflammation and dopaminergic neurodegeneration in a preclinical animal model of Parkinson's 
disease. J. Neuroimmune Pharmacol. 11, 259-278. doi: 10.1007/s11481-0169650-4

Ginhoux, F., and Jung, S. (2014). Monocytes and macrophages: developmental pathways and tissue homeostasis. Nat. Rev. Immunol. 14, 392-404. doi: 10.1038/ nri3671

Giunti, D., Parodi, B., Cordano, C., Uccelli, A., and Kerlero de Rosbo, N. (2014). Can we switch microglia's phenotype to foster neuroprotection? Focus on multiple sclerosis. Immunology 141, 328-339. doi: 10.1111/imm.12177

Goldwurm, S., Di Fonzo, A., Simons, E. J., Rohe, C. F., Zini, M., Canesi, M., et al. (2005). The G6055A (G2019S) mutation in LRRK2 is frequent in both early and late onset Parkinson's disease and originates from a common ancestor. J. Med. Genet. 42, e65. doi: 10.1136/jmg.2005.035568

Gonzalez, H., Elgueta, D., Montoya, A., and Pacheco, R. (2014). Neuroimmune regulation of microglial activity involved in neuroinflammation and neurodegenerative diseases. J. Neuroimmunol. 274, 1-13. doi: 10.1016/j.jneuroim.2014.07.012

Graeber, M. B. (2010). Changing face of microglia. Science 330, 783-788. doi: $10.1126 /$ science.1190929

Hamza, T. H., Zabetian, C. P., Tenesa, A., Laederach, A., Montimurro, J., Yearout, D., et al. (2010). Common genetic variation in the HLA region is associated with late-onset sporadic Parkinson's disease. Nat. Genet. 42, 781-785. doi: $10.1038 /$ ng. 642

Hantraye, P., Brouillet, E., Ferrante, R., Palfi, S., Dolan, R., Matthews, R. T., et al. (1996). Inhibition of neuronal nitric oxide synthase prevents MPTP-induced parkinsonism in baboons. Nat. Med. 2, 1017-1021. doi: 10.1038/nm0996-1017

Harms, A. S., Barnum, C. J., Ruhn, K. A., Varghese, S., Trevino, I., Blesch, A., et al. (2011). Delayed dominant-negative TNF gene therapy halts progressive loss of nigral dopaminergic neurons in a rat model of Parkinson's disease. Mol. Ther. 19, 46-52. doi: 10.1038/mt.2010.217

Hasegawa, E., Takeshige, K., Oishi, T., Murai, Y., and Minakami, S. (1990). 1-Methyl-4-phenylpyridinium (MPP+) induces NADH-dependent superoxide formation and enhances NADH-dependent lipid peroxidation in bovine heart submitochondrial particles. Biochem. Biophys. Res. Commun. 170, 1049-1055. doi: 10.1016/0006-291X(90)90498-C

Hawkes, C. H., Del Tredici, K., and Braak, H. (2009). Parkinson's disease: the dual hit theory revisited. Ann. N. Y. Acad. Sci. 1170, 615-622. doi: 10.1111/j.17496632.2009.04365.x

He, Y., Appel, S., and Le, W. (2001). Minocycline inhibits microglial activation and protects nigral cells after 6-hydroxydopamine injection into mouse striatum. Brain Res. 909, 187-193. doi: 10.1016/S0006-8993(01)02681-6

Heng, Y., Zhang, Q. S., Mu, Z., Hu, J. F., Yuan, Y. H., and Chen, N. H. (2016). Ginsenoside Rg1 attenuates motor impairment and neuroinflammation in the MPTP-probenecid-induced parkinsonism mouse model by targeting alpha-synuclein abnormalities in the substantia nigra. Toxicol. Lett. 243, 7-21. doi: 10.1016/j.toxlet.2015.12.005

Herber, D. L., Maloney, J. L., Roth, L. M., Freeman, M. J., Morgan, D., and Gordon, M. N. (2006). Diverse microglial responses after intrahippocampal administration of lipopolysaccharide. Glia 53, 382-391. doi: 10.1002/glia.20272

Hill-Burns, E. M., Factor, S. A., Zabetian, C. P., Thomson, G., and Payami, H. (2011). Evidence for more than one Parkinson's disease-associated variant within the HLA region. PLoS ONE 6:e27109. doi: 10.1371/journal.pone.0027109

Hirsch, E. C., and Hunot, S. (2009). Neuroinflammation in Parkinson's disease: a target for neuroprotection? Lancet Neurol. 8, 382-397. doi: 10.1016/S14744422(09)70062-6

Holmqvist, S., Chutna, O., Bousset, L., Aldrin-Kirk, P., Li, W., Bjorklund, T., et al. (2014). Direct evidence of Parkinson pathology spread from the gastrointestinal tract to the brain in rats. Acta Neuropathol. 128, 805-820. doi: 10.1007/s00401014-1343-6

Hu, X., and Ivashkiv, L. B. (2009). Cross-regulation of signaling pathways by interferon-gamma: implications for immune responses and autoimmune diseases. Immunity 31, 539-550. doi: 10.1016/j.immuni.2009.09.002

Hunot, S., and Hirsch, E. C. (2003). Neuroinflammatory processes in Parkinson's disease. Ann. Neurol. 53(Suppl. 3), S49-S58. doi: 10.1002/ana.10481

Iannaccone, S., Cerami, C., Alessio, M., Garibotto, V., Panzacchi, A., Olivieri, S., et al. (2013). In vivo microglia activation in very early dementia with Lewy bodies, comparison with Parkinson's disease. Parkinsonism Relat. Disord. 19, 47-52. doi: 10.1016/j.parkreldis.2012.07.002
Imamura, K., Hishikawa, N., Sawada, M., Nagatsu, T., Yoshida, M., and Hashizume, Y. (2003). Distribution of major histocompatibility complex class II-positive microglia and cytokine profile of Parkinson's disease brains. Acta Neuropathol. 106, 518-526. doi: 10.1007/s00401-003-0766-2

Javed, H., Azimullah, S., Haque, M. E., and Ojha, S. K. (2016). Cannabinoid type 2 (CB2) receptors activation protects against oxidative stress and neuroinflammation associated dopaminergic neurodegeneration in rotenone model of Parkinson's disease. Front. Neurosci. 10:321. doi: 10.3389/fnins.2016. 00321

Jiang, H., Li, L. J., Wang, J., and Xie, J. X. (2008). Ghrelin antagonizes MPTPinduced neurotoxicity to the dopaminergic neurons in mouse substantia nigra. Exp. Neurol. 212, 532-537. doi: 10.1016/j.expneurol.2008.05.006

Jing, H., Wang, S., Wang, M., Fu, W., Zhang, C., and Xu, D. (2017). Isobavachalcone attenuates MPTP-induced Parkinson's disease in mice by inhibition of microglial activation through NF-kappaB pathway. PLoS ONE 12:e0169560. doi: 10.1371/journal.pone.0169560

Joniec-Maciejak, I., Ciesielska, A., Wawer, A., Sznejder-Pacholek, A., Schwenkgrub, J., Cudna, A., et al. (2014). The influence of AAV2-mediated gene transfer of human IL-10 on neurodegeneration and immune response in a murine model of Parkinson's disease. Pharmacol. Rep. 66, 660-669. doi: 10.1016/j.pharep.2014.03.008

Kawanokuchi, J., Mizuno, T., Takeuchi, H., Kato, H., Wang, J., Mitsuma, N., et al. (2006). Production of interferon-gamma by microglia. Mult. Scler. 12, 558-564. doi: $10.1177 / 1352458506070763$

Kawanokuchi, J., Shimizu, K., Nitta, A., Yamada, K., Mizuno, T., Takeuchi, H., et al. (2008). Production and functions of IL-17 in microglia. J. Neuroimmunol. 194, 54-61. doi: 10.1016/j.jneuroim.2007.11.006

Keller, A. F., Gravel, M., and Kriz, J. (2011). Treatment with minocycline after disease onset alters astrocyte reactivity and increases microgliosis in SOD1 mutant mice. Exp. Neurol. 228, 69-79. doi: 10.1016/j.expneurol.2010.12.010

Khan, M. M., Kempuraj, D., Thangavel, R., and Zaheer, A. (2013). Protection of MPTP-induced neuroinflammation and neurodegeneration by Pycnogenol. Neurochem. Int. 62, 379-388. doi: 10.1016/j.neuint.2013.01.029

Kierdorf, K., and Prinz, M. (2013). Factors regulating microglia activation. Front. Cell Neurosci. 7:44. doi: 10.3389/fncel.2013.00044

Kim, B. W., Koppula, S., Kumar, H., Park, J. Y., Kim, I. W., More, S. V., et al. (2015). alpha-Asarone attenuates microglia-mediated neuroinflammation by inhibiting NF kappa B activation and mitigates MPTP-induced behavioral deficits in a mouse model of Parkinson's disease. Neuropharmacology 97, 46-57. doi: 10.1016/j.neuropharm.2015.04.037

Kim, S. R., Chen, X., Oo, T. F., Kareva, T., Yarygina, O., Wang, C., et al. (2011). Dopaminergic pathway reconstruction by Akt/Rheb-induced axon regeneration. Ann. Neurol. 70, 110-120. doi: 10.1002/ana.22383

Kim, S. R., Kareva, T., Yarygina, O., Kholodilov, N., and Burke, R. E. (2012). AAV transduction of dopamine neurons with constitutively active Rheb protects from neurodegeneration and mediates axon regrowth. Mol. Ther. 20, 275-286. doi: $10.1038 / \mathrm{mt} .2011 .213$

Kim, W. G., Mohney, R. P., Wilson, B., Jeohn, G. H., Liu, B., and Hong, J. S. (2000). Regional difference in susceptibility to lipopolysaccharide-induced neurotoxicity in the rat brain: role of microglia. J. Neurosci. 20, 6309-6316.

Kortekaas, R., Leenders, K. L., van Oostrom, J. C., Vaalburg, W., Bart, J., Willemsen, A. T., et al. (2005). Blood-brain barrier dysfunction in parkinsonian midbrain in vivo. Ann. Neurol. 57, 176-179. doi: 10.1002/ana.20369

Kruger, R., Kuhn, W., Muller, T., Woitalla, D., Graeber, M., Kosel, S., et al. (1998). Ala30Pro mutation in the gene encoding alpha-synuclein in Parkinson's disease. Nat. Genet. 18, 106-108. doi: 10.1038/ng0298-106

Lacey, D. C., Achuthan, A., Fleetwood, A. J., Dinh, H., Roiniotis, J., Scholz, G. M., et al. (2012). Defining GM-CSF- and macrophage-CSF-dependent macrophage responses by in vitro models. J. Immunol. 188, 5752-5765. doi: 10.4049/ jimmunol.1103426

Lanciego, J. L., Barroso-Chinea, P., Rico, A. J., Conte-Perales, L., Callen, L., Roda, E., et al. (2011). Expression of the mRNA coding the cannabinoid receptor 2 in the pallidal complex of Macaca fascicularis. J. Psychopharmacol. 25, 97-104. doi: 10.1177/0269881110367732

Langston, J. W., Ballard, P., Tetrud, J. W., and Irwin, I. (1983). Chronic Parkinsonism in humans due to a product of meperidine-analog synthesis. Science 219, 979-980. doi: 10.1126/science.6823561 
Langston, J. W., Irwin, I., Langston, E. B., and Forno, L. S. (1984). 1-Methyl-4phenylpyridinium ion (MPP+): identification of a metabolite of MPTP, a toxin selective to the substantia nigra. Neurosci. Lett. 48, 87-92. doi: 10.1016/03043940(84)90293-3

Lawson, L. J., Perry, V. H., Dri, P., and Gordon, S. (1990). Heterogeneity in the distribution and morphology of microglia in the normal adult mouse brain. Neuroscience 39, 151-170. doi: 10.1016/0306-4522(90)90229-W

Liu, B. (2006). Modulation of microglial pro-inflammatory and neurotoxic activity for the treatment of Parkinson's disease. AAPS J. 8, E606-E621. doi: 10.1208/ aapsj080369

Liu, Y., Holdbrooks, A. T., De Sarno, P., Rowse, A. L., Yanagisawa, L. L., McFarland, B. C., et al. (2014). Therapeutic efficacy of suppressing the Jak/STAT pathway in multiple models of experimental autoimmune encephalomyelitis. J. Immunol. 192, 59-72. doi: 10.4049/jimmunol.1301513

Liu, Z., and Lenardo, M. J. (2012). The role of LRRK2 in inflammatory bowel disease. Cell Res. 22, 1092-1094. doi: 10.1038/cr.2012.42

Loane, D. J., and Byrnes, K. R. (2010). Role of microglia in neurotrauma. Neurotherapeutics 7, 366-377. doi: 10.1016/j.nurt.2010.07.002

Long-Smith, C. M., Sullivan, A. M., and Nolan, Y. M. (2009). The influence of microglia on the pathogenesis of Parkinson's disease. Prog. Neurobiol. 89, 277-287. doi: 10.1016/j.pneurobio.2009.08.001

Lyons, A., Downer, E. J., Crotty, S., Nolan, Y. M., Mills, K. H., and Lynch, M. A. (2007). CD200 ligand receptor interaction modulates microglial activation in vivo and in vitro: a role for IL-4. J. Neurosci. 27, 8309-8313. doi: 10.1523/ JNEUROSCI.1781-07.2007

Mahad, D. J., and Ransohoff, R. M. (2003). The role of MCP-1 (CCL2) and CCR2 in multiple sclerosis and experimental autoimmune encephalomyelitis (EAE). Semin. Immunol. 15, 23-32. doi: 10.1016/S1044-5323(02)00125-2

Mandrekar-Colucci, S., Karlo, J. C., and Landreth, G. E. (2012). Mechanisms underlying the rapid peroxisome proliferator-activated receptor-gammamediated amyloid clearance and reversal of cognitive deficits in a murine model of Alzheimer's disease. J. Neurosci. 32, 10117-10128. doi: 10.1523/JNEUROSCI. 5268-11.2012

Maresz, K., Carrier, E. J., Ponomarev, E. D., Hillard, C. J., and Dittel, B. N. (2005). Modulation of the cannabinoid CB2 receptor in microglial cells in response to inflammatory stimuli. J. Neurochem. 95, 437-445. doi: 10.1111/j.1471-4159. 2005.03380.x

Markey, S. P., Johannessen, J. N., Chiueh, C. C., Burns, R. S., and Herkenham, M. A. (1984). Intraneuronal generation of a pyridinium metabolite may cause drug-induced parkinsonism. Nature 311, 464-467. doi: 10.1038/311464a0

Mascarenhas, J. O., Cross, N. C., and Mesa, R. A. (2014). The future of JAK inhibition in myelofibrosis and beyond. Blood Rev. 28, 189-196. doi: 10.1016/j. blre.2014.06.002

McCoy, M. K., Ruhn, K. A., Martinez, T. N., McAlpine, F. E., Blesch, A., and Tansey, M. G. (2008). Intranigral lentiviral delivery of dominant-negative TNF attenuates neurodegeneration and behavioral deficits in hemiparkinsonian rats. Mol. Ther. 16, 1572-1579. doi: 10.1038/mt.2008.146

McGeer, P. L., Itagaki, S., Boyes, B. E., and McGeer, E. G. (1988). Reactive microglia are positive for HLA-DR in the substantia nigra of Parkinson's and Alzheimer's disease brains. Neurology 38, 1285-1291. doi: 10.1212/WNL.38.8.1285

McGeer, P. L., and McGeer, E. G. (2004). Inflammation and neurodegeneration in Parkinson's disease. Parkinsonism Relat. Disord. 10(Suppl. 1), S3-S7. doi: 10.1016/j.parkreldis.2004.01.005

Michell-Robinson, M. A., Touil, H., Healy, L. M., Owen, D. R., Durafourt, B. A., Bar-Or, A., et al. (2015). Roles of microglia in brain development, tissue maintenance and repair. Brain 138, 1138-1159. doi: 10.1093/brain/awv066

Michelucci, A., Heurtaux, T., Grandbarbe, L., Morga, E., and Heuschling, P. (2009). Characterization of the microglial phenotype under specific pro-inflammatory and anti-inflammatory conditions: effects of oligomeric and fibrillar amyloid-beta. J. Neuroimmunol. 210, 3-12. doi: 10.1016/j.jneuroim.2009. 02.003

Mittelbronn, M., Dietz, K., Schluesener, H. J., and Meyermann, R. (2001). Local distribution of microglia in the normal adult human central nervous system differs by up to one order of magnitude. Acta Neuropathol. 101, 249-255.

Moehle, M. S., Webber, P. J., Tse, T., Sukar, N., Standaert, D. G., DeSilva, T. M., et al. (2012). LRRK2 inhibition attenuates microglial inflammatory responses. J. Neurosci. 32, 1602-1611. doi: 10.1523/JNEUROSCI.5601-11.2012
Moehle, M. S., and West, A. B. (2015). M1 and M2 immune activation in Parkinson's disease: foe and ally? Neuroscience 302, 59-73. doi: 10.1016/j. neuroscience.2014.11.018

Moon, M., Kim, H. G., Hwang, L., Seo, J. H., Kim, S., Hwang, S., et al. (2009). Neuroprotective effect of ghrelin in the 1-methyl-4-phenyl-1,2,3,6tetrahydropyridine mouse model of Parkinson's disease by blocking microglial activation. Neurotox. Res. 15, 332-347. doi: 10.1007/s12640-009-9037-x

More, S., and Choi, D. K. (2017). Neuroprotective role of atractylenolide-I in an in vitro and in vivo model of Parkinson's disease. Nutrients 9, E451. doi: 10.3390/nu9050451

Morgan, D., Gordon, M. N., Tan, J., Wilcock, D., and Rojiani, A. M. (2005). Dynamic complexity of the microglial activation response in transgenic models of amyloid deposition: implications for Alzheimer therapeutics. J. Neuropathol. Exp. Neurol. 64, 743-753. doi: 10.1097/01.jnen.0000178444.33972.e0

Mount, M. P., Lira, A., Grimes, D., Smith, P. D., Faucher, S., Slack, R., et al. (2007). Involvement of interferon-gamma in microglial-mediated loss of dopaminergic neurons. J. Neurosci. 27, 3328-3337. doi: 10.1523/JNEUROSCI.5321-06.2007

Nagatsu, T., Mogi, M., Ichinose, H., and Togari, A. (2000). Changes in cytokines and neurotrophins in Parkinson's disease. J. Neural Transm. Suppl. 60, 277-290. doi: 10.1007/978-3-7091-6301-6_19

Nakagawa, Y., and Chiba, K. (2015). Diversity and plasticity of microglial cells in psychiatric and neurological disorders. Pharmacol. Ther. 154, 21-35. doi: 10.1016/j.pharmthera.2015.06.010

Nam, J. H., Leem, E., Jeon, M. T., Jeong, K. H., Park, J. W., Jung, U. J., et al. (2015). Induction of GDNF and BDNF by hRheb(S16H) transduction of SNpc neurons: neuroprotective mechanisms of hRheb(S16H) in a model of Parkinson's disease. Mol. Neurobiol. 51, 487-499. doi: 10.1007/s12035-014-8729-2

Neumann, H., Kotter, M. R., and Franklin, R. J. (2009). Debris clearance by microglia: an essential link between degeneration and regeneration. Brain 132, 288-295. doi: 10.1093/brain/awn109

Nicklas, W. J., Vyas, I., and Heikkila, R. E. (1985). Inhibition of NADH-linked oxidation in brain mitochondria by 1-methyl-4-phenyl-pyridine, a metabolite of the neurotoxin, 1-methyl-4-phenyl-1,2,5,6-tetrahydropyridine. Life Sci. 36, 2503-2508. doi: 10.1016/0024-3205(85)90146-8

Nimmerjahn, A., Kirchhoff, F., and Helmchen, F. (2005). Resting microglial cells are highly dynamic surveillants of brain parenchyma in vivo. Science 308, 1314-1318. doi: 10.1126/science. 1110647

Ninds Exploratory Trials in Parkinson Disease (Net-Pd) Fs-Zone Investigators (2015). Pioglitazone in early Parkinson's disease: a phase 2, multicentre, doubleblind, randomised trial. Lancet Neurol. 14, 795-803. doi: 10.1016/S14744422(15)00144- 1

Ninds Net-Pd Investigators (2008). A pilot clinical trial of creatine and minocycline in early Parkinson disease: 18-month results. Clin. Neuropharmacol. 31, 141-150. doi: 10.1097/WNF.0b013e3181342f32

Noda, H., Takeuchi, H., Mizuno, T., and Suzumura, A. (2013). Fingolimod phosphate promotes the neuroprotective effects of microglia. J. Neuroimmunol. 256, 13-18. doi: 10.1016/j.jneuroim.2012.12.005

Olah, M., Biber, K., Vinet, J., and Boddeke, H. W. (2011). Microglia phenotype diversity. CNS Neurol. Disord. Drug Targets 10, 108-118. doi: 10.2174/ 187152711794488575

Onaivi, E. S. (2006). Neuropsychobiological evidence for the functional presence and expression of cannabinoid CB2 receptors in the brain. Neuropsychobiology 54, 231-246. doi: 10.1159/000100778

Orihuela, R., McPherson, C. A., and Harry, G. J. (2016). Microglial M1/M2 polarization and metabolic states. Br. J. Pharmacol. 173, 649-665. doi: 10.1111/ bph.13139

Pan-Montojo, F., Anichtchik, O., Dening, Y., Knels, L., Pursche, S., Jung, R., et al. (2010). Progression of Parkinson's disease pathology is reproduced by intragastric administration of rotenone in mice. PLOS ONE 5:e8762. doi: 10.1371/journal.pone.0008762

Pan-Montojo, F., Schwarz, M., Winkler, C., Arnhold, M., O'Sullivan, G. A., Pal, A., et al. (2012). Environmental toxins trigger PD-like progression via increased alpha-synuclein release from enteric neurons in mice. Sci. Rep. 2:898. doi: 10.1038/srep00898

Paolicelli, R. C., Bolasco, G., Pagani, F., Maggi, L., Scianni, M., Panzanelli, P., et al. (2011). Synaptic pruning by microglia is necessary for normal brain development. Science 333, 1456-1458. doi: 10.1126/science.1202529 
Pena-Altamira, E., Prati, F., Massenzio, F., Virgili, M., Contestabile, A., Bolognesi, M. L., et al. (2016). Changing paradigm to target microglia in neurodegenerative diseases: from anti-inflammatory strategy to active immunomodulation. Expert Opin. Ther. Targets 20, 627-640. doi: 10.1517/14728222.2016.1121237

Pennathur, S., Jackson-Lewis, V., Przedborski, S., and Heinecke, J. W. (1999). Mass spectrometric quantification of 3-nitrotyrosine, ortho-tyrosine, and o,o' dityrosine in brain tissue of 1-methyl-4-phenyl-1,2,3, 6-tetrahydropyridinetreated mice, a model of oxidative stress in Parkinson's disease. J. Biol. Chem. 274, 34621-34628. doi: 10.1074/jbc.274.49.34621

Pettersen, J. S., Fuentes-Duculan, J., Suarez-Farinas, M., Pierson, K. C., PittsKiefer, A., Fan, L., et al. (2011). Tumor-associated macrophages in the cutaneous SCC microenvironment are heterogeneously activated. J. Invest. Dermatol. 131, 1322-1330. doi: 10.103/jid.2011.9

Phillips, R. J., Walter, G. C., Wilder, S. L., Baronowsky, E. A., and Powley, T. L. (2008). Alpha-synuclein-immunopositive myenteric neurons and vagal preganglionic terminals: autonomic pathway implicated in Parkinson's disease? Neuroscience 153, 733-750. doi: 10.1016/j.neuroscience.2008.02.074

Pisanu, A., Lecca, D., Mulas, G., Wardas, J., Simbula, G., Spiga, S., et al. (2014). Dynamic changes in pro- and anti-inflammatory cytokines in microglia after PPAR-gamma agonist neuroprotective treatment in the MPTPp mouse model of progressive Parkinson's disease. Neurobiol. Dis. 71, 280-291. doi: 10.1016/j. nbd.2014.08.011

Pocock, J. M., and Kettenmann, H. (2007). Neurotransmitter receptors on microglia. Trends Neurosci. 30, 527-535. doi: 10.1016/j.tins.2007.07.007

Polymeropoulos, M. H., Lavedan, C., Leroy, E., Ide, S. E., Dehejia, A., Dutra, A., et al. (1997). Mutation in the alpha-synuclein gene identified in families with Parkinson's disease. Science 276, 2045-2047. doi: 10.1126/science.276.5321.2045

Price, D. A., Martinez, A. A., Seillier, A., Koek, W., Acosta, Y., Fernandez, E., et al. (2009). WIN55,212-2, a cannabinoid receptor agonist, protects against nigrostriatal cell loss in the 1-methyl-4-phenyl-1,2,3,6-tetrahydropyridine mouse model of Parkinson's disease. Eur. J. Neurosci. 29, 2177-2186. doi: 10.1111/j.1460-9568.2009.06764.x

Przedborski, S., Jackson-Lewis, V., Yokoyama, R., Shibata, T., Dawson, V. L., and Dawson, T. M. (1996). Role of neuronal nitric oxide in 1-methyl-4-phenyl1,2,3,6-tetrahydropyridine (MPTP)-induced dopaminergic neurotoxicity. Proc. Natl. Acad. Sci. U.S.A. 93, 4565-4571. doi: 10.1073/pnas.93.10.4565

Qian, L., and Flood, P. M. (2008). Microglial cells and Parkinson's disease. Immunol. Res. 41, 155-164. doi: 10.1007/s12026-008-8018-0

Ramsay, R. R., Salach, J. I., Dadgar, J., and Singer, T. P. (1986). Inhibition of mitochondrial NADH dehydrogenase by pyridine derivatives and its possible relation to experimental and idiopathic parkinsonism. Biochem. Biophys. Res. Commun. 135, 269-275. doi: 10.1016/0006-291X(86)90972-1

Ransohoff, R. M., and Brown, M. A. (2012). Innate immunity in the central nervous system. J. Clin. Invest. 122, 1164-1171. doi: 10.1172/JCI58644

Ransohoff, R. M., and Cardona, A. E. (2010). The myeloid cells of the central nervous system parenchyma. Nature 468, 253-262. doi: 10.1038/nature 09615

Rau, R. (2002). Adalimumab (a fully human anti-tumour necrosis factor alpha monoclonal antibody) in the treatment of active rheumatoid arthritis: the initial results of five trials. Ann. Rheum. Dis. 61(Suppl. 2), ii70-ii73. doi: 10.1136/ard. 61.suppl_2.ii70

Rees, K., Stowe, R., Patel, S., Ives, N., Breen, K., Clarke, C. E., et al. (2011). Nonsteroidal anti-inflammatory drugs as disease-modifying agents for Parkinson's disease: evidence from observational studies. Cochrane Database Syst. Rev. 11, CD008454. doi: 10.1002/14651858.cd008454.pub2

Rite, I., Machado, A., Cano, J., and Venero, J. L. (2007). Blood-brain barrier disruption induces in vivo degeneration of nigral dopaminergic neurons. J. Neurochem. 101, 1567-1582. doi: 10.1111/j.1471-4159.2007.04567.x

Rojanathammanee, L., Murphy, E. J., and Combs, C. K. (2011). Expression of mutant alpha-synuclein modulates microglial phenotype in vitro. J. Neuroinflammation 8:44. doi: 10.1186/1742-2094-8-44

Roodveldt, C., Labrador-Garrido, A., Gonzalez-Rey, E., Lachaud, C. C., Guilliams, T., Fernandez-Montesinos, R., et al. (2013). Preconditioning of microglia by alpha-synuclein strongly affects the response induced by toll-like receptor (TLR) stimulation. PLoS ONE 8:e79160. doi: 10.1371/journal.pone. 0079160

Russo, I., Berti, G., Plotegher, N., Bernardo, G., Filograna, R., Bubacco, L., et al. (2015). Leucine-rich repeat kinase 2 positively regulates inflammation and down-regulates NF-kappaB p50 signaling in cultured microglia cells. J. Neuroinflammation 12, 230. doi: 10.1186/s12974-015-0449-7

Samii, A., Etminan, M., Wiens, M. O., and Jafari, S. (2009). NSAID use and the risk of Parkinson's disease: systematic review and meta-analysis of observational studies. Drugs Aging 26, 769-779. doi: 10.2165/11316780-000000000-00000

Saunders, J. A., Estes, K. A., Kosloski, L. M., Allen, H. E., Dempsey, K. M., Torres-Russotto, D. R., et al. (2012). CD4+ regulatory and effector/memory T cell subsets profile motor dysfunction in Parkinson's disease. J. Neuroimmune Pharmacol. 7, 927-938. doi: 10.1007/s11481-012-9402-Z

Schmid, C. D., Melchior, B., Masek, K., Puntambekar, S. S., Danielson, P. E., Lo, D. D., et al. (2009). Differential gene expression in LPS/IFNgamma activated microglia and macrophages: in vitro versus in vivo. J. Neurochem. 109(Suppl. 1), 117-125. doi: 10.1111/j.1471-4159.2009.05984.x

Schmidt, S., Linnartz, B., Mendritzki, S., Sczepan, T., Lubbert, M., Stichel, C. C., et al. (2011). Genetic mouse models for Parkinson's disease display severe pathology in glial cell mitochondria. Hum. Mol. Genet. 20, 1197-1211. doi: $10.1093 / \mathrm{hmg} / \mathrm{ddq} 564$

Schwartz, M., Butovsky, O., Bruck, W., and Hanisch, U. K. (2006). Microglial phenotype: is the commitment reversible? Trends Neurosci. 29, 68-74.

Schwenkgrub, J., Joniec-Maciejak, I., Sznejder-Pacholek, A., Wawer, A., Ciesielska, A., Bankiewicz, K., et al. (2013). Effect of human interleukin10 on the expression of nitric oxide synthases in the MPTP-based model of Parkinson's disease. Pharmacol. Rep. 65, 44-49. doi: 10.1016/S1734-1140(13) 70962-9

Shaunak, S., Brown, P., and Morgan-Hughes, J. A. (1995). Exacerbation of idiopathic Parkinson's disease by naproxen. BMJ 311, 422. doi: 10.1136/bmj. $311.7002 .422 \mathrm{~b}$

Sierra, S., Luquin, N., Rico, A. J., Gomez-Bautista, V., Roda, E., Dopeso-Reyes, I. G., et al. (2015). Detection of cannabinoid receptors CB1 and CB2 within basal ganglia output neurons in macaques: changes following experimental parkinsonism. Brain Struct. Funct. 220, 2721-2738. doi: 10.1007/s00429-0140823-8

Singleton, A., and Hardy, J. (2011). A generalizable hypothesis for the genetic architecture of disease: pleomorphic risk loci. Hum. Mol. Genet. 20, R158-R162. doi: $10.1093 / \mathrm{hmg} / \mathrm{ddr} 358$

Singleton, A. B., Farrer, M., Johnson, J., Singleton, A., Hague, S., Kachergus, J., et al. (2003). alpha-Synuclein locus triplication causes Parkinson's disease. Science 302, 841. doi: 10.1126/science. 1090278

Smeyne, R. J., and Jackson-Lewis, V. (2005). The MPTP model of Parkinson's disease. Brain Res. Mol. Brain Res. 134, 57-66. doi: 10.1016/j.molbrainres.2004. 09.017

Spillantini, M. G., Schmidt, M. L., Lee, V. M., Trojanowski, J. Q., Jakes, R., and Goedert, M. (1997). Alpha-synuclein in lewy bodies. Nature 388, 839-840. doi: $10.1038 / 42166$

Sriram, K., Matheson, J. M., Benkovic, S. A., Miller, D. B., Luster, M. I., and O'Callaghan, J. P. (2002). Mice deficient in TNF receptors are protected against dopaminergic neurotoxicity: implications for Parkinson's disease. FASEB J. 16, 1474-1476. doi: 10.1096/fj.02-0216fje

Steurer, J. (2011). [Nonsteroidal analgesics have a protective effect against Parkinson disease]. Praxis 100, 617-618. doi: 10.1024/1661-8157/a000535

Stevens, B., Allen, N. J., Vazquez, L. E., Howell, G. R., Christopherson, K. S., Nouri, N., et al. (2007). The classical complement cascade mediates CNS synapse elimination. Cell 131, 1164-1178. doi: 10.1016/j.cell.2007.10.036

$\mathrm{Su}, \mathrm{X}$., Federoff, H. J., and Maguire-Zeiss, K. A. (2009). Mutant alpha-synuclein overexpression mediates early proinflammatory activity. Neurotox. Res. 16, 238-254. doi: 10.1007/s12640-009-9053-x

Su, X., Maguire-Zeiss, K. A., Giuliano, R., Prifti, L., Venkatesh, K., and Federoff, H. J. (2008). Synuclein activates microglia in a model of Parkinson's disease. Neurobiol. Aging 29, 1690-1701. doi: 10.1016/j.neurobiolaging.2007.04.006

Sunnemark, D., Eltayeb, S., Nilsson, M., Wallstrom, E., Lassmann, H., Olsson, T., et al. (2005). CX3CL1 (fractalkine) and CX3CR1 expression in myelin oligodendrocyte glycoprotein-induced experimental autoimmune encephalomyelitis: kinetics and cellular origin. J. Neuroinflammation 2, 17.

Svensson, E., Horvath-Puho, E., Thomsen, R. W., Djurhuus, J. C., Pedersen, L., Borghammer, P., et al. (2015). Vagotomy and subsequent risk of Parkinson's disease. Ann. Neurol. 78, 522-529. doi: 10.1002/ana.24448

Swiatkiewicz, M., Zaremba, M., Joniec, I., Czlonkowski, A., and KurkowskaJastrzebska, I. (2013). Potential neuroprotective effect of ibuprofen, insights 
from the mice model of Parkinson's disease. Pharmacol. Rep. 65, 1227-1236. doi: 10.1016/S1734-1140(13)71480-4

Takeda, K., and Akira, S. (2004). TLR signaling pathways. Semin. Immunol. 16, 3-9. doi: 10.1016/j.smim.2003.10.003

Tang, Y., Li, T., Li, J., Yang, J., Liu, H., Zhang, X. J., et al. (2014). Jmjd3 is essential for the epigenetic modulation of microglia phenotypes in the immune pathogenesis of Parkinson's disease. Cell Death Differ. 21, 369-380. doi: 10.1038/cdd.2013.159

Teismann, P., and Ferger, B. (2001). Inhibition of the cyclooxygenase isoenzymes COX-1 and COX-2 provide neuroprotection in the MPTP-mouse model of Parkinson's disease. Synapse 39, 167-174. doi: 10.1002/1098-2396(200102)39: $2<167::$ AID-SYN8>3.0.CO;2-U

Theodore, S., Cao, S., McLean, P. J., and Standaert, D. G. (2008). Targeted overexpression of human alpha-synuclein triggers microglial activation and an adaptive immune response in a mouse model of Parkinson disease. J. Neuropathol. Exp. Neurol. 67, 1149-1158. doi: 10.1097/NEN. 0b013e31818e5e99

Tremblay, M. E., Lowery, R. L., and Majewska, A. K. (2010). Microglial interactions with synapses are modulated by visual experience. PLoS Biol. 8:e1000527. doi: 10.1371/journal.pbio.1000527

Tsai, S. J., Kuo, W. W., Liu, W. H., and Yin, M. C. (2010). Antioxidative and antiinflammatory protection from carnosine in the striatum of MPTP-treated mice. J. Agric. Food Chem. 58, 11510-11516. doi: 10.1021/jf103258p

Ulusoy, A., Rusconi, R., Perez-Revuelta, B. I., Musgrove, R. E., Helwig, M., WinzenReichert, B., et al. (2013). Caudo-rostral brain spreading of alpha-synuclein through vagal connections. EMBO Mol. Med. 5, 1051-1059. doi: 10.1002/ emmm.201302475

Villaran, R. F., Espinosa-Oliva, A. M., Sarmiento, M., De Pablos, R. M., Arguelles, S., Delgado-Cortes, M. J., et al. (2010). Ulcerative colitis exacerbates lipopolysaccharide-induced damage to the nigral dopaminergic system: potential risk factor in Parkinson's disease. J. Neurochem. 114, 1687-1700. doi: $10.1111 / j .1471-4159.2010 .06879 . x$

Vogel, D. Y., Vereyken, E. J., Glim, J. E., Heijnen, P. D., Moeton, M., van der Valk, P., et al. (2013). Macrophages in inflammatory multiple sclerosis lesions have an intermediate activation status. J. Neuroinflammation 10:35. doi: 10.1186/1742-2094-10-35

Wahner, A. D., Bronstein, J. M., Bordelon, Y. M., and Ritz, B. (2007). Nonsteroidal anti-inflammatory drugs may protect against Parkinson disease. Neurology 69, 1836-1842. doi: 10.1212/01.wnl.0000279519.99344.ad

Wang, S., Jing, H., Yang, H., Liu, Z., Guo, H., Chai, L., et al. (2015). Tanshinone I selectively suppresses pro-inflammatory genes expression in activated microglia and prevents nigrostriatal dopaminergic neurodegeneration in a mouse model of Parkinson's disease. J. Ethnopharmacol. 164, 247-255. doi: 10.1016/j.jep.2015. 01.042

Watanabe, H., Muramatsu, Y., Kurosaki, R., Michimata, M., Matsubara, M., Imai, Y., et al. (2004). Protective effects of neuronal nitric oxide synthase inhibitor in mouse brain against MPTP neurotoxicity: an immunohistological study. Eur. Neuropsychopharmacol. 14, 93-104. doi: 10.1016/S0924-977X(03) 00065-8

Watson, M. B., Richter, F., Lee, S. K., Gabby, L., Wu, J., Masliah, E., et al. (2012). Regionally-specific microglial activation in young mice over-expressing human wildtype alpha-synuclein. Exp. Neurol. 237, 318-334. doi: 10.1016/j.expneurol. 2012.06.025
Weisser, S. B., McLarren, K. W., Kuroda, E., and Sly, L. M. (2013). Generation and characterization of murine alternatively activated macrophages. Methods Mol. Biol. 946, 225-239. doi: 10.1007/978-1-62703-128-8_14

Wilms, H., Sievers, J., Rickert, U., Rostami-Yazdi, M., Mrowietz, U., and Lucius, R. (2010). Dimethylfumarate inhibits microglial and astrocytic inflammation by suppressing the synthesis of nitric oxide, IL-1beta, TNF-alpha and IL-6 in an in-vitro model of brain inflammation. J. Neuroinflammation 7:30. doi: 10.1186/ 1742-2094-7-30

Wilms, H., Zecca, L., Rosenstiel, P., Sievers, J., Deuschl, G., and Lucius, R. (2007). Inflammation in Parkinson's diseases and other neurodegenerative diseases: cause and therapeutic implications. Curr. Pharm. Des. 13, 1925-1928. doi: $10.2174 / 138161207780858429$

Wu, D. C., Jackson-Lewis, V., Vila, M., Tieu, K., Teismann, P., Vadseth, C., et al. (2002). Blockade of microglial activation is neuroprotective in the 1-methyl-4-phenyl-1,2,3,6-tetrahydropyridine mouse model of Parkinson disease. J. Neurosci. 22, 1763-1771.

Xu, Y. D., Cui, C., Sun, M. F., Zhu, Y. L., Chu, M., Shi, Y. W., et al. (2017). Neuroprotective effects of loganin on MPTP-induced Parkinson's disease mice: neurochemistry, glial reaction and autophagy studies. J. Cell. Biochem. [Epub ahead of print], doi: 10.1002/jcb.26010

Yang, W., Chen, Y. H., Liu, H., and Qu, H. D. (2015). Neuroprotective effects of piperine on the 1-methyl-4-phenyl-1,2,3,6-tetrahydropyridine-induced Parkinson's disease mouse model. Int. J. Mol. Med. 36, 1369-1376. doi: 10.3892/ ijmm.2015.2356

Yiangou, Y., Facer, P., Durrenberger, P., Chessell, I. P., Naylor, A., Bountra, C., et al. (2006). COX-2, CB2 and P2X7-immunoreactivities are increased in activated microglial cells/macrophages of multiple sclerosis and amyotrophic lateral sclerosis spinal cord. BMC Neurol. 6:12. doi: 10.1186/1471-2377-6-12

Zarranz, J. J., Alegre, J., Gomez-Esteban, J. C., Lezcano, E., Ros, R., Ampuero, I., et al. (2004). The new mutation, E46K, of alpha-synuclein causes Parkinson and Lewy body dementia. Ann. Neurol. 55, 164-173. doi: 10.1002/ana.10795

Zhang, Q. S., Heng, Y., Yuan, Y. H., and Chen, N. H. (2017). Pathological alphasynuclein exacerbates the progression of Parkinson's disease through microglial activation. Toxicol. Lett. 265, 30-37. doi: 10.1016/j.toxlet.2016.11.002

Zhao, C., Ling, Z., Newman, M. B., Bhatia, A., and Carvey, P. M. (2007). TNF-alpha knockout and minocycline treatment attenuates blood-brain barrier leakage in MPTP-treated mice. Neurobiol. Dis. 26, 36-46. doi: 10.1016/j.nbd.2006. 11.012

Ziegler-Heitbrock, L., Ancuta, P., Crowe, S., Dalod, M., Grau, V., Hart, D. N., et al. (2010). Nomenclature of monocytes and dendritic cells in blood. Blood 116, e74-e80. doi: 10.1182/blood-2010-02-258558

Conflict of Interest Statement: The authors declare that the research was conducted in the absence of any commercial or financial relationships that could be construed as a potential conflict of interest.

Copyright (c) 2017 Subramaniam and Federoff. This is an open-access article distributed under the terms of the Creative Commons Attribution License (CC BY). The use, distribution or reproduction in other forums is permitted, provided the original author(s) or licensor are credited and that the original publication in this journal is cited, in accordance with accepted academic practice. No use, distribution or reproduction is permitted which does not comply with these terms. 